\title{
Multi-scale enhancement of climate prediction over land by increasing the model sensitivity to vegetation variability in EC-Earth
}

\author{
Andrea Alessandri ${ }^{1}$ (D) Franco Catalano ${ }^{1}$ Matteo De Felice ${ }^{1}$. \\ Bart Van Den Hurk ${ }^{2}$ Francisco Doblas Reyes ${ }^{3,5,6}$ - Souhail Boussetta ${ }^{4}$. \\ Gianpaolo Balsamo ${ }^{4}$ Paul A. Miller ${ }^{7}$
}

Received: 19 November 2015 / Accepted: 17 April 2016 / Published online: 5 October 2016

(C) The Author(s) 2016. This article is published with open access at Springerlink.com

\begin{abstract}
The EC-Earth earth system model has been recently developed to include the dynamics of vegetation. In its original formulation, vegetation variability is simply operated by the Leaf Area Index (LAI), which affects climate basically by changing the vegetation physiological resistance to evapotranspiration. This coupling has been found to have only a weak effect on the surface climate modeled by EC-Earth. In reality, the effective sub-grid vegetation fractional coverage will vary seasonally and at interannual time-scales in response to leaf-canopy growth, phenology and senescence. Therefore it affects biophysical parameters such as the albedo, surface roughness and soil field capacity. To adequately represent this effect in EC-Earth, we included an exponential dependence of the vegetation cover on the LAI. By comparing two sets of simulations performed with and without the new variable
\end{abstract}

Andrea Alessandri

andrea.alessandri@enea.it

1 Agenzia Nazionale per le nuove Tecnologie, l'energia e lo sviluppo economico sostenibile (ENEA), Bldg C59, Sp. 118 CR Casaccia, Via Anguillarese, 301, Santa Maria di Galeria, 00123 Rome, Italy

2 Royal Netherlands Meteorological Institute, De Bilt, The Netherlands

3 Institut Català de Ciències del Clima (IC3), Barcelona, Spain

4 European Centre for Medium-Range Weather Forecasts, Shinfield Park, Reading, UK

5 Institució Catalana de Recerca i Estudis Avançats (ICREA), Barcelona, Spain

6 Barcelona Supercomputing Center-Centro Nacional de Supercomputación (BSC-CNS), Barcelona, Spain

7 Department of Physical Geography and Ecosystem Science, Lund University, Lund, Sweden fractional-coverage parameterization, spanning from centennial (twentieth century) simulations and retrospective predictions to the decadal (5-years), seasonal and weather time-scales, we show for the first time a significant multiscale enhancement of vegetation impacts in climate simulation and prediction over land. Particularly large effects at multiple time scales are shown over boreal winter middleto-high latitudes over Canada, West US, Eastern Europe, Russia and eastern Siberia due to the implemented timevarying shadowing effect by tree-vegetation on snow surfaces. Over Northern Hemisphere boreal forest regions the improved representation of vegetation cover tends to correct the winter warm biases, improves the climate change sensitivity, the decadal potential predictability as well as the skill of forecasts at seasonal and weather time-scales. Significant improvements of the prediction of $2 \mathrm{~m}$ temperature and rainfall are also shown over transitional land surface hot spots. Both the potential predictability at decadal time-scale and seasonal-forecasts skill are enhanced over Sahel, North American Great Plains, Nordeste Brazil and South East Asia, mainly related to improved performance in the surface evapotranspiration.

Keywords Climate prediction - Climate simulation . Vegetation dynamics $\cdot$ Land-climate interactions $\cdot$ Earth system modeling $\cdot$ Multi-scale prediction enhancement

\section{Introduction}

The notion of seamless prediction is now at the hearth of the World Meteorological Organization strategic framework aimed at the development of a new generation of dynamical climate forecasting tools based on Earth System Models (ESMs; World Meteorological Organization 2015). 
The seamless concept originates from the fact that the Earth System exhibits a wide range of dynamical, physical, biological, and chemical interactions involving spatial and temporal variability continuously spanning all weather/climate scales. This motivates the climate forecasting community towards the inclusion in the forecast models of verifiable biophysical processes that can lead to the enhancement of the predictions across the Weather-synoptic, seasonal, decadal and climate change time-scales (Shukla 2009; World Meteorological Organization 2015). The vegetation state and variability characterize the evolution of important biophysical parameters such as surface resistance to evapotranspiration, albedo, roughness length and soil water exploitable by roots (e.g. Bonan 2008). The vegetation dynamics can span a wide and continuous range of time scales from sub-seasonal, seasonal, interannual, decadal and centennial modulated by leaf-canopy growth, phenology, senescence and competition (Bonan 2008), therefore implying potential predictive power for the climate system that may exploit improvements across time scales (Hoskins 2013).

Previous studies discussed the impact of LAI seasonality (Lawrence and Slingo 2004; Hurk et al. 2003) and inter-annual variability (Guillevic et al. 2002) showing a non-negligible impact on the simulated surface climate over land (Alessandri et al. 2007). The observational study by Alessandri and e A. Navarra, (2008) clearly identified a link between rainfall and vegetation variability indicating an important delayed feedback of the land surface to the precipitation pattern and a possible contribution to predictability on seasonal and longer time scales (Alessandri and Navarra 2008). The LAI directly affects surface climate by determining the total amount of evapotranspirating leaf surface per unit area of vegetation, therefore determining the surface resistance to evapotranspiration (Bonan 2008; Lawrence and Slingo 2004). On the other hand, the LAI also defines the density of the vegetation canopies and the effective vegetation cover over bare soils or snow surfaces, therefore further affecting surface roughness length, evapotranspiration resistance, albedo, and effective field capacity (Bonan 2008). Boussetta et al. (2013) introduced a monthly climatology for LAI based on a MODIS satellite product (Myneni et al. 2002) within the European Centre for Medium-Range Weather Forecast (ECMWF) Integrated Forecasting System (IFS) to replace the static LAI previously used. They showed that this results in a reduction of near-surface temperature errors in the tropical and mid-latitude areas, especially during spring and summer seasons. Recently, Boussetta et al. (2015) showed that assimilating LAI (and surface albedo) product within the ECMWF land surface scheme has an impact on the surface fluxes. When used in the coupled land-atmosphere system the forecasts reduces the near-surface air temperature and humidity errors both in wet and dry cases. Previous predictability experiments performed at seasonal-to-decadal time scales using the European Consortium Earth System Model (ECEarth) evidenced weak sensitivity of model results to vegetation changes (Weiss et al. 2012, 2014) and with only marginal enhancement of potential predictability (Weiss et al. 2012) and insignificant forecast skill enhancements at both seasonal (Weiss et al. 2012) and decadal (Weiss et al. 2014) timescales.

However, in previous works the vegetation density and the effective fractional coverage were constant in time, as assumed in the original formulation of the land surface model included in both IFS and in EC-Earth (Hydrology Tiled ECMWF Scheme of Surface Exchanges over Land, HTESSEL; Balsamo et al. 2009). Therefore the biophysical parameters related to vegetation cover (surface resistance to evapotranspiration, albedo, interception area, roughness length and soil field capacity) are likewise not varying in time.

The land surface models included in current ESMs should aim to adequately represent vegetation phenomena to provide the land surface influence on climate variability. State-of-the-art ESMs, like EC-Earth, still lack an appropriate treatment of vegetation able to take into account the effects of vegetation cover variability. The effective vegetation cover variability at seasonal and at interannual timescales can be modeled as a function of leaf-canopy growth, phenology and senescence following an exponential attenuation with the increase in LAI (e.g. Lawrence and Slingo 2004; Bonan 2008). To properly represent vegetation variability in HTESSEL and the coupling with the overlying atmosphere (IFS) in EC-Earth, we designed a modified version of the code to allow vegetation effective fractional coverage to change as a function of LAI for both low and high vegetation. To this aim an exponential dependence of the vegetation densities to LAI has been introduced in HTESSEL following the approach described in Alessandri et al. (2007) and similarly to what already implemented in other land surface models (e.g. Organizing Carbon and Hydrology In Dynamic Ecosystems, ORCHIDEE; Krinner et al. 2005). A set of simulations at multiple time scales has been performed with both the original (CTRL) and modified (MODIF) version of EC-Earth2.4. A weather forecast case study for March 2015 over Europe has also been included by using the CTRL and MODIF versions of the atmosphere-only implementation of IFS as in the ECMWF operational weather forecasting system.

The present study is organized as follows: Sect. 2 defines the methodology by describing the EC-Earth ESM (Sect. 2.1) and the improved representation of vegetation variability introduced in the modified version (Sect. 2.2). Furthermore, in Sects. 2.3 and 2.4 the set of experiments is described, while the observations/reanalysis data used 
as reference are introduced in Sect. 2.5. Section 3 reports the effects on EC-Earth simulated air temperature biases (Sect. 3.1) and on climate change sensitivity (Sect. 3.2). In Sect. 4 , the effects on potential predictability is evaluated at the decadal time scale (up to 5 years). Section 5 assesses the impact on shorter term forecasts, with the main focus on seasonal predictions and also considering the case study over Europe at the weather forecast time-scale (3-days) for March 2015. Finally, in Sect. 6 a summary of the main conclusions is given.

\section{Method}

Two sets of historical simulations and retrospective predictions are performed using (1) standard (CTRL) and (2) modified (MODIF) versions of the EC-Earth2.4 ESM (Hazeleger et al. 2012; Weiss et al. 2014). The MODIF version allows vegetation fractional coverage to change as a function of Leaf Area Index (LAI) for both low and high vegetation (see Sect. 2.2). The same configuration and resolution of the EC-Earth2.4 ESM has been used in all climate-simulation and retrospective climate-prediction experiments performed in this study (Sect. 2.3). For the March 2015 Numerical Weather Prediction (NWP) case study we applied the CTRL and MODIF versions of the atmosphere-only implementation of IFS as in the ECMWF operational weather forecasting system (Sect. 2.4).

\subsection{EC-Earth2.4}

The EC-Earth (Hazeleger et al. 2012; Weiss et al. 2014) ESM is based on the operational seasonal forecast system of ECMWF. EC-Earth version 2.4 is composed of an atmospheric model initially derived from the Integrated Forecast System cycle 31R1 of the ECMWF (ECMWF 2007), ocean model NEMO version 2 (Madec 2008), sea ice model LIM2 (Fichefet and Morales Maqueda 1997), and the land surface scheme HTESSEL (Balsamo et al. 2009). The same resolution of the EC-Earth2.4 ESM has been used in all simulations and retrospective prediction experiments performed in this study (see Sect. 2.3). The atmospheric model (IFS, cycle 31R1; ECMWF 2007) is used at its standard T159 spectral horizontal resolution, corresponding to an associated Gaussian grid of approximately $1.12^{\circ} \times 1.12^{\circ}(\sim 125 \mathrm{~km})$, with 62 vertical levels. The ocean model NEMO is run with an ORCA-1 configuration, which has an Arakawa C-grid with about $1^{\circ}$ horizontal resolution and 42 vertical levels. HTESSEL and LIM2 share the same horizontal resolution of the atmosphere and of the ocean, respectively.

HTESSEL solves the energy and water balance for up to six different land surface tiles that may be present over land (bare ground, low and high vegetation, intercepted water by vegetation, and shaded and exposed snow). Surface radiative, latent heat and sensible heat fluxes are calculated as a weighted average of the values over each tile. The latent and sensible heat fluxes are computed using a resistance approach involving aerodynamic and canopy resistances formulation to account for the transfer efficiency of heat and water vapor over a vertical temperature and humidity gradient. Cover fractions of snow (separated in exposed snow that is on ground or low vegetation, and snow that is shaded under high vegetation) and intercepted water by vegetation are calculated dynamically. The background tile fractions (bare ground, $A_{b}$, low and high vegetation maximum fractional coverages, $A_{l, h}$ ) and vegetation densities $\left(C_{l, h}\right)$ are prescribed from a static land-use map ensuring that each grid point sum to unity:

$1=A_{l} \times C_{l}+A_{h} \times C_{h}+A_{b}$

EC-Earth can be run in coupled mode with the state-ofthe-art dynamic vegetation and ecosystem model LundPotsdam-Jena General Ecosystem Simulator (LPJ-GUESS; Smith et al. 2001). To capture the major plant types determining global biomes, LPJ-GUESS uses 11 Plant Functional Types (PFTs) for natural vegetation, where 2 are herbaceous and 9 are woody types. These modeled PFTs are defined using fixed parameters to determine their morphology, phenology, and shade tolerance. As reported by Weiss et al. (2014), the coupling of vegetation dynamics with ECEarth is performed by only providing the time-varying LAI values of high and low vegetation to the climate model. This can only affect climate by changing the vegetation physiological resistance to evapotranspiration. Therefore, in the original version, albedo, surface roughness length, and soil water exploitable by roots for evapotranspiration do not vary with vegetation state (LAI). Even surface albedo of snow in vegetation-covered areas does not depend on LAI values in this version of Weiss et al. (2014). The lack of albedo dependence on LAI over snow covered areas was motivated in Weiss et al. (2014) by an exploration of Moderate Resolution Imaging Spectroradiometer (MODIS) data that revealed a compensation between the changes in visible and near infrared reflectance (Teuling and Seneviratne 2008). However, this negligible sensitivity of albedo to LAI only holds under the applied assumption that snow and effective vegetation fractions remain unchanged (Weiss et al. 2014), which is not very realistic (e.g. Bonan 2008).

\subsection{EC-Earth2.4 modified version}

In the standard EC-Earth version (CTRL), the fractional coverage of bare soil $\left(A_{b}\right)$ and the maximum fractional coverages $\left(A_{h}, A_{l}\right)$ and densities $\left(C_{h}, C_{l}\right)$ of vegetation are fixed in time. To introduce a more realistic representation 
of vegetation variability in HTESSEL and its coupling with the overlying atmosphere, we designed a modified version (MODIF) that allows vegetation density to change as a function of LAI for both low and high vegetation. Similarly to what described in Alessandri et al. (2007) for the ORCHIDEE land model (Krinner et al. 2005), the vegetation densities $\left(C_{h}, C_{l}\right)$ are made to vary in time $(t)$ according to the Lambert Beer (LB) law of extinction of light under a vegetation canopy:

$C_{l, h}(t)=\left(1-e^{-k L A I_{l, h}(t)}\right)$

where $\mathrm{k}=0.5$. Note that also the bare soil tile fraction is now changing with time and is computed as the residual that is not covered by vegetation.

$$
A_{b}(t)=1-A_{l} \times C_{l}\left[L A I_{l}(t)\right]-A_{h} \times C_{h}\left[L A I_{h}(t)\right]
$$

The difference between CTRL and MODIF versions of ECEarth2.4 is schematized in Fig. 1. Differently from CTRL (Fig. 1a), the effective vegetation cover can vary in time in the modified version (Fig. 1b) as a function of vegetation state (LAI) variability (Fig. 1c). Accordingly, the albedo, surface roughness length and soil water exploitable by roots for evapotranspiration will vary following the variability of the effective vegetation cover at interannual (Fig. 2a, b) and seasonal (Fig. 2c, d) time scales. Also, the fraction of snow that is shaded by the high vegetation will now depend on $\operatorname{LAI}_{h}(t)$ (Fig. 1b). This is an important factor in boreal forests during winter because, by shading snow, vegetation can reduce albedo from the $0.7-0.9$ values typical of white snow to $0.25-0.35$ of snow beneath high vegetation (Hartman 1994).

\subsection{EC-Earth2.4 experiments}

The following set of historical simulations and retrospective predictions has been performed with both CTRL and MODIF versions of EC-Earth2.4.

\subsubsection{Historical centennial simulations}

The historical simulations cover the period 1900-2010, and have been performed by prescribing changing boundary conditions, obtained from available observations, following the protocol from phase 5 of the Coupled Model Intercomparison Project (CMIP5, Meehl et al. 2009; Taylor et al. 2012). The external forcing (greenhouse gases, ozone, natural and anthropogenic aerosols and solar activity) is prescribed based on the CMIP5-recommended historical datasets (Moss et al. 2010). The simulations were started from preindustrial conditions (1850-on), previously generated by spinning up the model for 700 years imposing preindustrial boundary forcing. Two members were generated for both $C T R L_{h i s t}$ and $M O D I F_{\text {hist }}$ experiments (see summary Table 1) by slightly perturbing the initial conditions (ICs) for 1st January 1900. The second member used the restart file from the day before (i.e. 30th instead of 31st December 1899 ) as the 1st January 1900 IC.
Fig. 1 Scheme summarizing a the original (CTRL) representation and $\mathbf{b}$ the modified (MODIF) version that introduces $\mathbf{c}$ the Lambert-Beer formulation of vegetation density $(\mathrm{Cv})$ as a function of Leaf Area Index (LAI) (a)
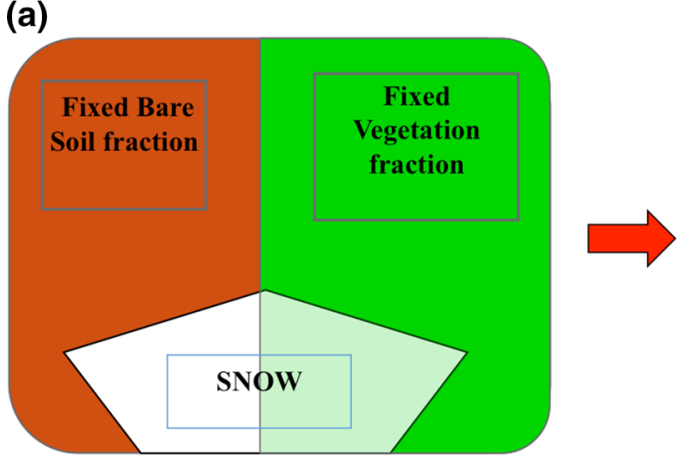

(b)

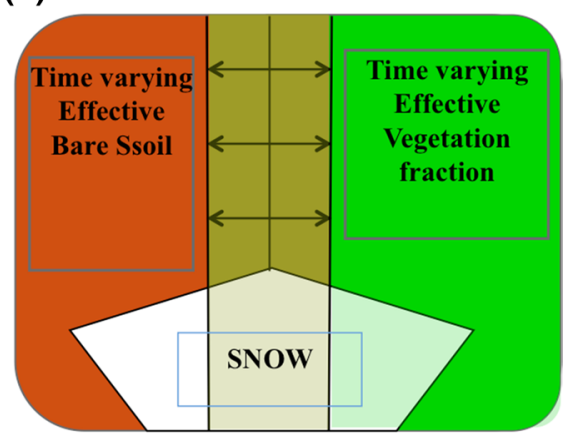

(c)

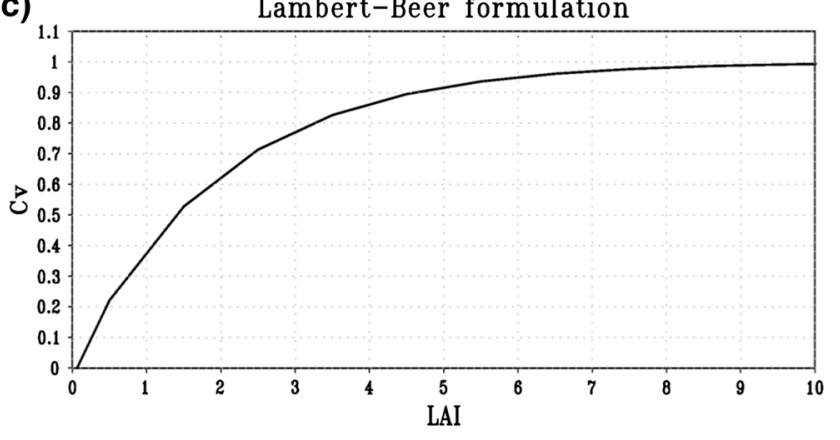




\section{Implemented effective cover interannual variability (std dev)}

(a)

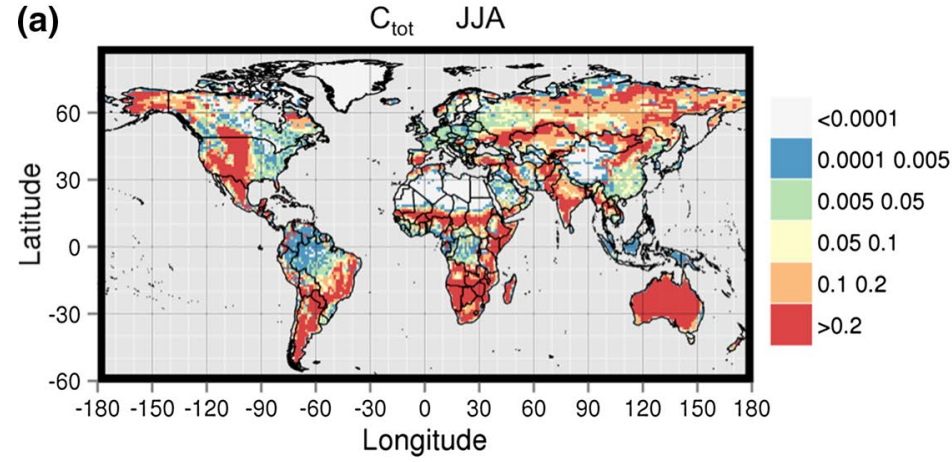

(c)

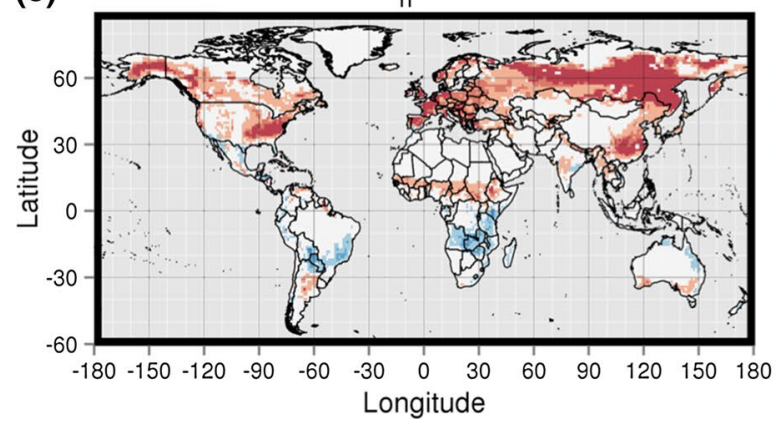

(b) $\quad \mathrm{C}_{\text {tot }}$ DJF

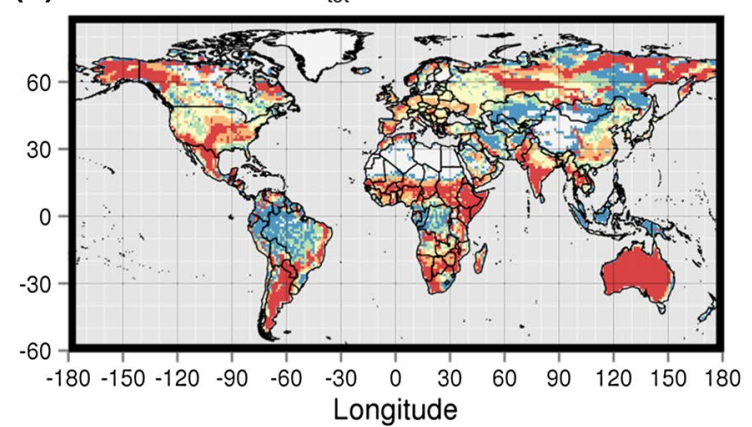

(d)

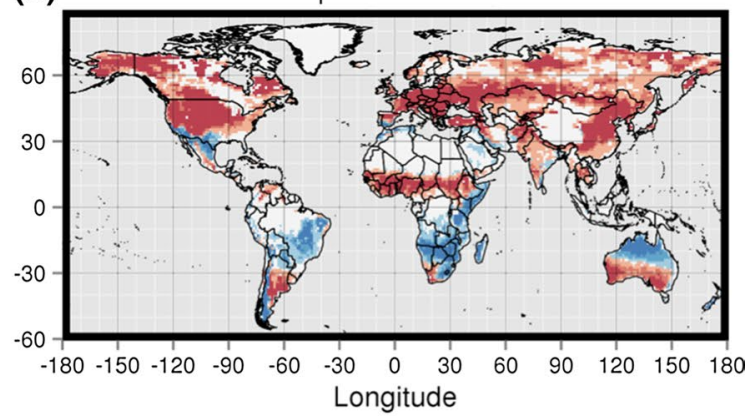

Fig. 2 Effective total vegetation cover $\left(c_{t o t}\right)$ inter-annual variability (standard deviation) implemented in MODIF version of EC-Earth

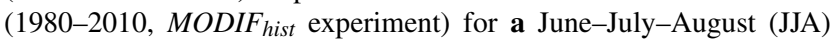

\subsubsection{Decadal predictability experiment}

Using ICs from the historical simulations performed with MODIF version of the model ( $\left.M O D I F_{\text {hist }}\right)$, a decadal predictability experiment is performed covering the period 1960-2010 with start dates taken every 5 years, i.e. the same configuration used for the CMIP5 decadal prediction experiment (Taylor et al. 2012). This experiment is executed as a "perfect model" exercise, implying an evaluation of the results against a reference model simulation. The predictability experiment has been performed for both $C T R L_{d e c}$ and $M O D I F_{d e c}$ versions by taking the model world, as represented by $M O D I F_{h i s t}$, as the reference (Table 1). Ensembles of 7-member predictions are then performed using perturbed atmospheric ICs, i.e. taking slightly lagged initial states from the historical simulation. For each experiment, we initialize the atmosphere January 1 st by using ICs from the end of 30 December as well as from the six preceding days of the $M O D I F_{\text {hist }}$ simulation to obtain an ensemble of seven atmospheric ICs for each start date of the hindcasts. The exactly same initialization for all model components of the $M O D I F_{d e c}$ and the $C T R L_{d e c}$ decadal predictability experiments is used, the only difference is that in $C T R L_{d e c}$ the new effective vegetation cover parameterization has been switched and b December-January-February (DJF). JJA minus DJF climatological seasonal cycle in MODIF for $\mathbf{c}$ high vegetation cover $\left(c_{h}\right)$ and d low vegetation cover $\left(c_{l}\right)$

off and as a consequence the vegetation densities are constant in time.

\subsubsection{Seasonal hindcasts experiment}

We performed a retrospective seasonal hindcast experiment with prescribed LAI from a dataset based on the third generation GIMMS and MODIS satellite observations (Zhu et al. 2013). The hindcasts setup is as follows (see summary Table 1): 7 months forecast length, 1st May and 1st November start dates, 10 members for each start date and for each of the 28 years (1982-2009). Atmospheric ICs for the seasonal hindcast experiment are taken from ERAINTERIM (Dee et al. 2011) and perturbations, generated by using the singular vector method (Magnusson et al. 2008), are applied to all the prognostic variables except humidity (Du et al. 2012). Land surface ICs are taken from ERA-land (Balsamo et al. 2015), while ocean ICs are from the 3D-Var five-member ensemble ocean re-analysis NEMOVAR-ORAS4 (Mogensen et al. 2012). Sea ice initialization was produced using five-member historical climate simulations performed with EC-Earth constrained by ocean and atmosphere observational data (Guemas et al. 2014). The exactly identical initialization for all model components of the modified $\left(M O D I F_{\text {seas }}\right)$ and the control 
$\left(C T R L_{\text {seas }}\right)$ hindcasts is used, the only difference is that in $C T R L_{\text {seas }}$ the new effective vegetation cover parameterization has been switched off and as a consequence the vegetation densities are constant in time.

\subsection{Atmosphere-only weather forecasts for march 2015}

To further verify the possible improvement of the predictions at the short weather time scale, a case study has been performed for March 2015 using the ECMWF operational weather forecasting system at 72-h lead time focusing on the European domain. The modified version of the ECMWF operational NWP system $\left(M O D I F_{N W P}\right)$ was derived in the same way as for EC-Earth2.4, i.e. by applying the same changes to the HTESSEL land surface model as described in Sect. 2.2. For spring 2015 the ECMWF weather forecasts using the original version of the HTESSEL land model $\left(C T R L_{N W P}\right)$ were affected by cold errors on $2 \mathrm{~m}$ temperature up to $4 \mathrm{~K}$ over Scandinavia region and moist bias on $2 \mathrm{~m}$ specific humidity of around $1 \mathrm{~g} /$ $\mathrm{kg}$ over the same region. Two forecast experiments using $M O D I F_{N W P}$ and $C T R L_{N W P}$, both initialized daily with the ECMWF operational analysis (Bonavita et al. 2016), have been performed for March 2015 using the high resolution deterministic IFS system. These forecasts have been operated at the operational T1279 spectral horizontal resolution (approximately $16 \mathrm{~km}$ ) with 137 vertical levels based on cycle 41R1 (ECMWF 2015). The land model HTESSEL shares the same horizontal resolution as the atmosphere. The only difference between the forecasts performed using $C T R L_{N W P}$ and $M O D I F_{N W P}$ is that the new effective vegetation cover parameterization has been switched off in $C T R L_{N W P}$ and, as a consequence, the vegetation densities are constant in time.

\subsection{Observations and reanalysis data}

The observationally-based LAI data has been obtained from a novel dataset based on the third generation GIMMS and MODIS satellite observations (Zhu et al. 2013). The LAI dataset was suitably pre-processed (monthly averaged, interpolated, gap-filled) to use it in the land surface scheme of EC-Earth (HTESSEL). The performance of retrospective forecasts is evaluated by taking as the reference the ERA-INTERIM reanalysis (Berrisford et al. 2009; Dee et al. 2011) for $2 \mathrm{~m}$-temperature and surface fluxes of latent and sensible heat, while the GPCP satellite-based dataset is used for precipitation (Adler 2003). In order to evaluate the climate-change signal in the historical simulations, observationally based monthly-mean land surface air temperature data are taken from the CRU dataset available from 1901-2013 (Harris et al. 2014)

\section{Effects on EC-Earth simulated climate}

\subsection{Surface air temperature bias}

The $2 \mathrm{~m}$ temperature simulated by EC-Earth2.4 is, on a global average, about $1 \mathrm{~K}$ cooler than that in ERAINTERIM. During the boreal winter, a positive temperature bias is observed over most of boreal forests in middle to high latitude North America, Eurasia and Siberia, in addition to the known problem of a warmer bias in Southern Oceans (Hazeleger et al. 2012; Sterl et al. 2012). The bias is negative elsewhere, in particular over the Arctic region, Greenland, Nordeste Brazil, Arabia, South Africa and Central Asia (Fig. 3a). During the boreal summer the cold biases tend to be smaller compared to the winter season and the regions with temperature climatology higher than observed are very limited over land and almost absent in boreal forest regions (Fig. 4a).

The analysis shows considerable sensitivity of ECEarth2.4 surface climate to the new variable vegetation cover parameterization. Figure $3 b$ shows the effect of modified scheme on surface air temperature during December-January-February (DJF). Particularly large effects are shown over boreal winter middle-to-high latitudes. Importantly, the cooling effect of the new parameterization appears to correct the warm biases of the control simulation over Euro-Asian boreal forests (Fig. 3a). Over the winter snowy boreal forests, this is primarily attributed to the albedo increase due to the reduced shadowing of the highly reflective snow by the high-tree vegetation (Fig. 5a). In fact, the introduced dependence of the vegetation density to LAI reduces the effective high-vegetation cover during winter (Fig. 2c) therefore increasing the fraction of the grid-point that is reflecting with the higher albedo of snow. Due to the sharp reduction of available solar radiation while proceeding to higher latitudes, the impact of albedo change on surface radiation and temperature is more effective at latitudes lower than $60^{\circ} \mathrm{N}$ (not shown). At latitudes higher than $60^{\circ} \mathrm{N}$, the influence of surface albedo decreases rapidly with the available solar radiation, leading to a less robust relationship and a weaker effect on temperature (Orsolini et al. 2013). Considering all grid points covered by snow (snow depth $\geq 10 \mathrm{~cm}$ for both MODIF and CTRL) in the $40-75 \mathrm{~N}$ latitude band, the linear regression of the MODIF-minusCTRL changes in temperature versus high vegetation cover $\left(A_{h} \cdot C_{h}\right.$ in Eq. 3) produces a regression coefficient of $+1.9 \mathrm{~K}$ (significantly different from zero at the $5 \%$ using Fisher significance test). This means that there is an expected averaged reduction of $1.9 \mathrm{~K}$ by removing high vegetation from 1.0 to 0.0 fractional coverage. The cooling effect of the new parameterization appears not effective in correcting the warm winter biases of the control 


\section{0-2010 historical simulations}

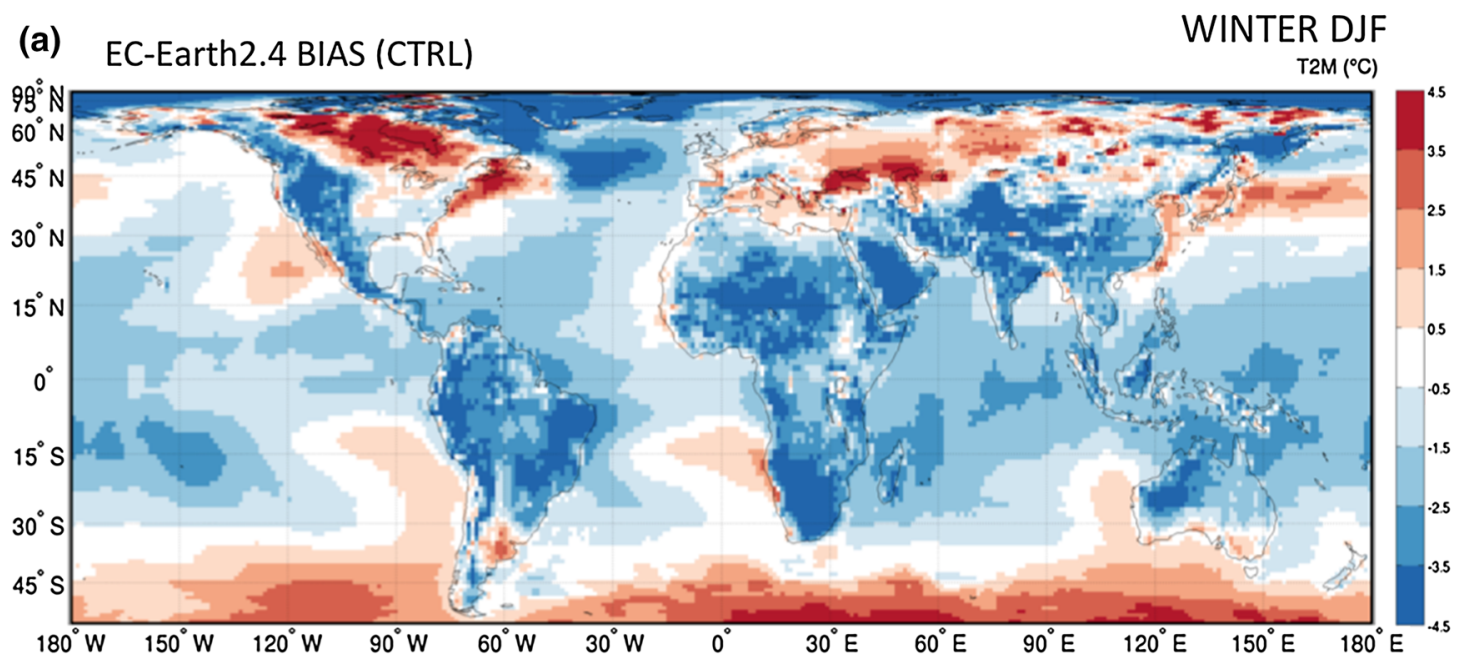

(b) T2m SENSITIVITY (MODIF minus CTRL)

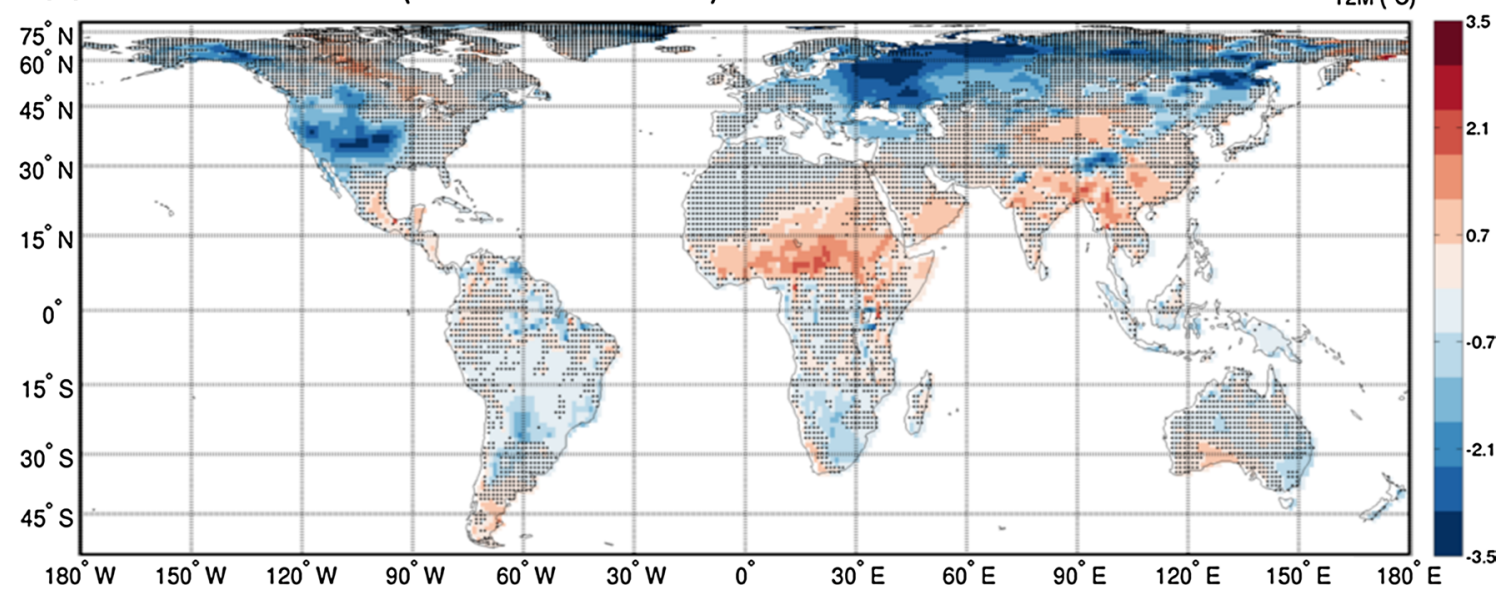

Fig. 3 Boreal winter (December-January-February) $2 \mathrm{~m}$ temperature of the historical simulations (1980-2010) a bias of the CTRL hist experiment with respect to ERA-INTERIM reanalysis and $\mathbf{b}$ sensitivity $\left(M O D I F_{\text {hist }}\right.$ minus $\left.C T R L_{\text {hist }}\right)$

over the high-latitude northern North America boreal forests (Fig. 3a). This could be related to the positive LAI bias in EC-Earth 2.4 originated by the excessive precipitation over northern North America documented in Weiss et al. (2014). In fact, the biased LAI over high-latitude northern North America boreal forests tends to be well above 3.0 all year round (Weiss et al. 2014) and therefore the winter reduction of high vegetation cover as represented by the LB formulation (Fig. 1c) is very limited compared to Euro-Asian forests (Fig. 2c). The effect during boreal summer tends to be smaller but still showing a large cooling over Northern Hemisphere high latitudes (Fig. 4b) that is associated with the increased albedo (Fig. 6a). In regions such as eastern Siberia and northwestern North America, the increased summer albedo appears related to the larger accumulation of snow during the colder winters that allows snow cover to persist longer during spring and summer months (not shown). As a consequence of the reduced vegetation cover during boreal winter (Fig. 2c, d), semiarid regions of Sahel, Mexico and South-East Asia appear affected by reduced vegetation evapotranspiration and consequent increased ratio between sensible and latent heat flux at the surface (bowen ratio; Fig. 5b). According to the mechanism proposed in Sutton et al. (2007), the temperature increase over these regions follows from the reduced efficiency of sensible heat exchange compared to the latent heat removal that can be accomplished by evapotranspiration. Similarly, increased bowen ratios associated with a reduced vegetation cover (Fig. 2c, d) characterize southwestern North America and sub-tropical Africa during boreal summer (Fig. 6b). On the other hand, the increased June-July-August (JJA) bowen ratio over most semi-arid Asian grassland and savannas is most likely related to 


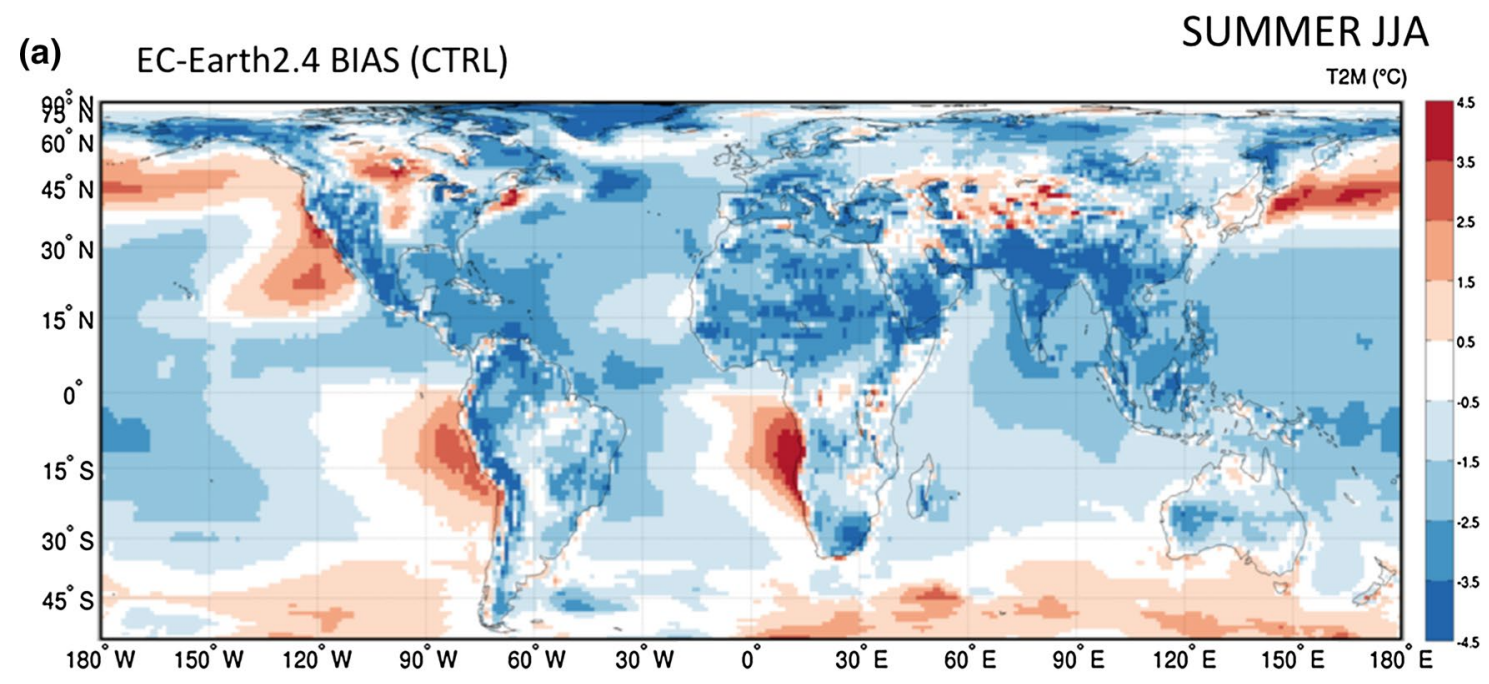

(b) SENSITIVITY (MODIF - CTRL)

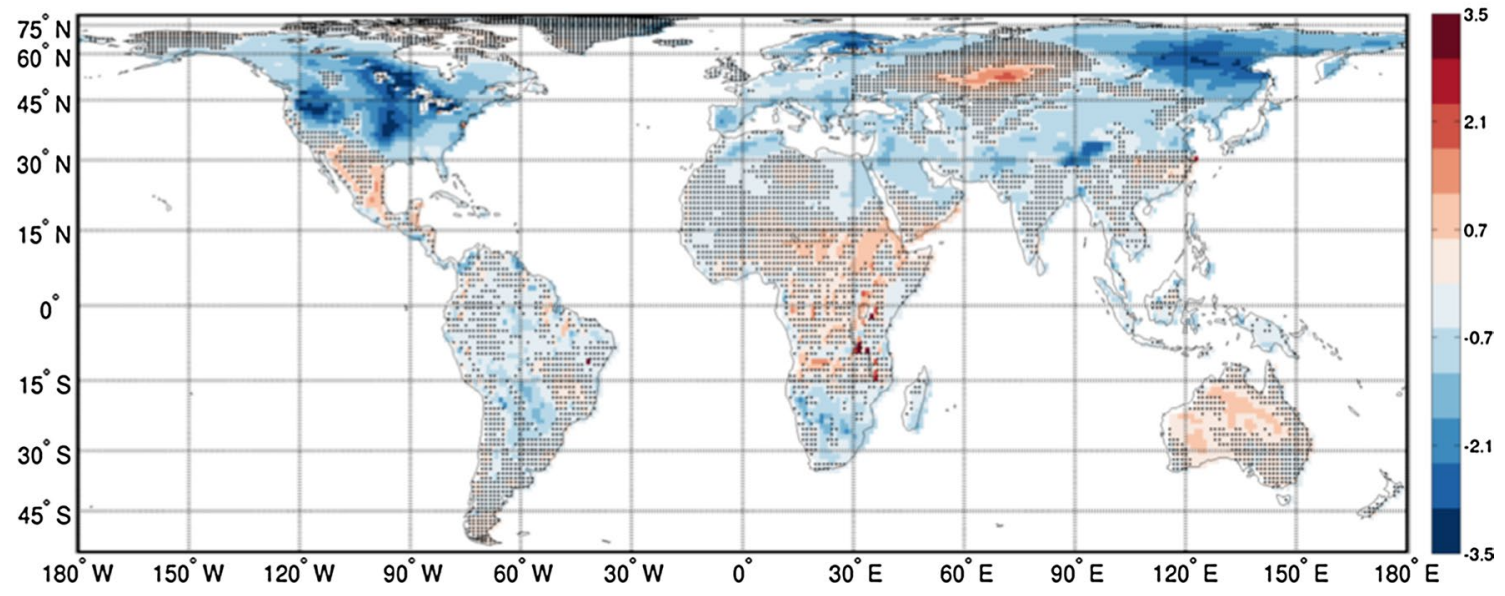

Fig. 4 Same as Fig. 3 but for boreal summer (June-July-August; JJA)

the reduced availability of soil water for evapotranspiration. Interestingly, negative bowen ratio changes are found over some mid-latitude areas during boreal summer, including central US Great Plains, northern North America and eastern Siberia (Fig. 6b). Again, this behavior appears consistent with the increased surface latent heat flux associated with expanded low and/or high vegetation cover (Fig. 2c, d) and is partially responsible of the reduced $2 \mathrm{~m}$ temperature over these regions.

\subsection{Wintertime climate change sensitivity during the twentieth century}

Figure 7 compares the boreal winter (DJF) 2 m-temperature change between the end (1980-2010) and the beginning (1910-1940) of the last century for CRU observations (Harris et al. 2014) (Fig. 7a), CTRL hist (Fig. 7b) and $M O D I F_{\text {hist }}$ (Fig. 7c). The larger temperature change observed during the last century occurred over middle to high latitudes of the Northern Hemisphere, in particular over Euro-Asian boreal forests (Fig. 7a). The CTRL experiment appears unable to represent the warming signal over boreal forests particularly in the Asian sector. On the other hand, MODIF hist reproduces much better the warming signal with respect to $C T R L_{\text {hist }}$ in the Northern Hemisphere (Figs. 7c, 8a). Again, the main mechanism is related to the albedo, which is reduced significantly in the MODIF hist experiment during the twentieth century (Fig. 8b) due to the increased shadowing of the highly reflective snow by the high-tree vegetation (Fig. 8c). In fact, the warmer conditions over middle-to-high latitudes driven by the radiative climate-change forcing lead to increased LAI and effective high-vegetation cover for $M O D I F_{\text {hist }}$, therefore leading to vegetation positive feedback on temperature change 


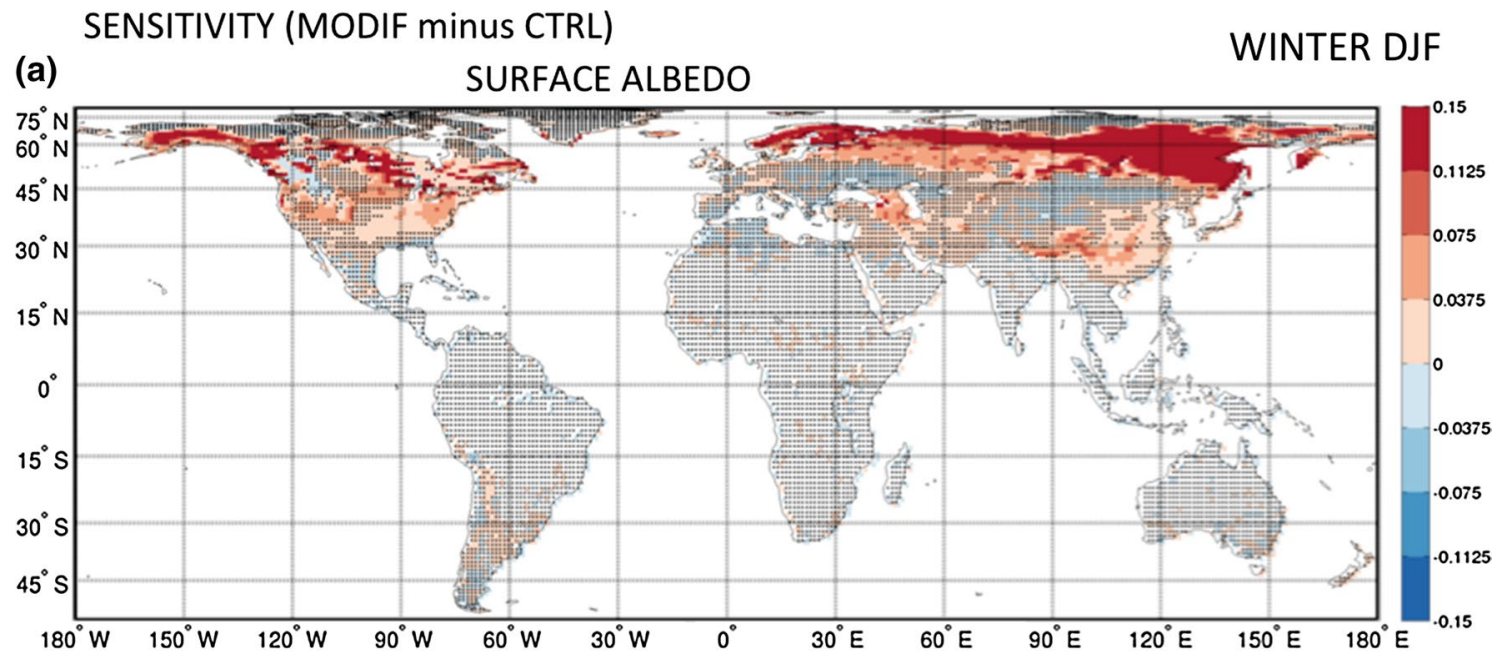

(b)

BOWEN RATIO

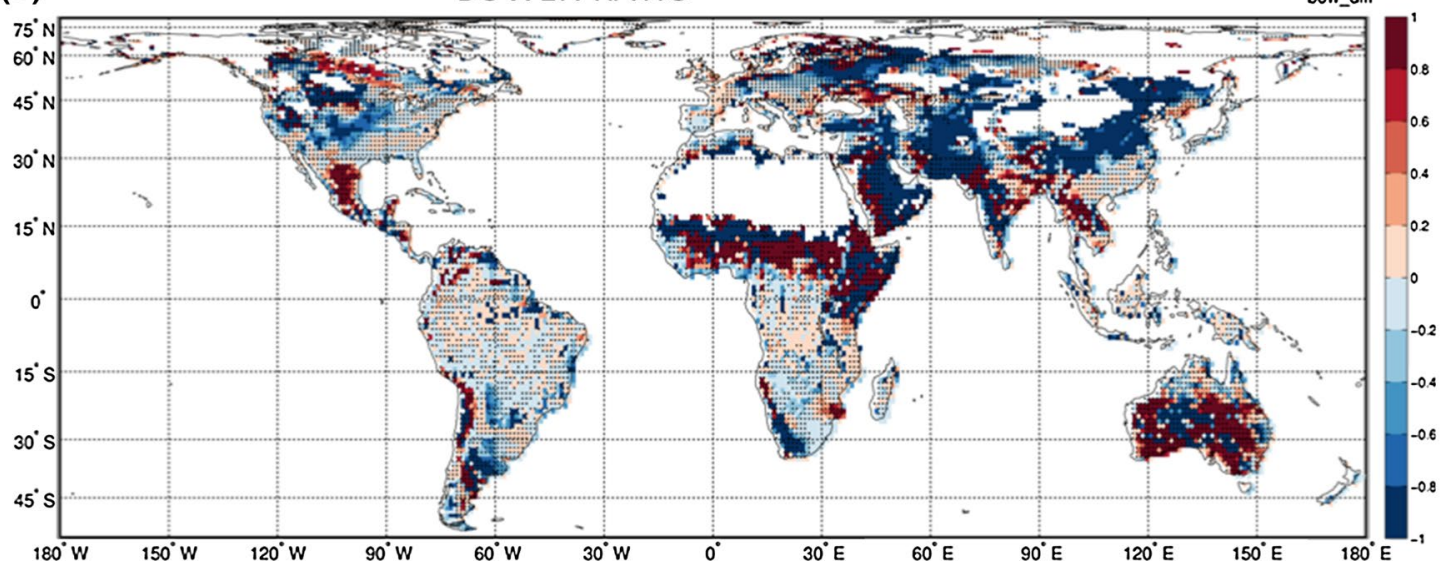

Fig. 5 Boreal winter (December-January-February) sensitivity (MODIF minus CTRL) in the historical simulations (1980-2010) for a albedo and $\mathbf{b}$ bowen ratio

during the period analyzed. The estimated (least square method) linear relation between albedo and high-vegetation cover $\left(A_{h} \cdot C_{h}\right.$ in Eq. 3$)$ changes over snow covered regions $(45 \mathrm{~N}-75 \mathrm{~N}$ latitudinal band; snow depth $\geq 10 \mathrm{~cm}$ ) has a slope of -0.30 , significantly different from zero at $5 \%$ level (Fisher parametric test). Correspondingly, the regression coefficient of the temperature change on the high vegetation cover change is 4.5 , which means that there is an averaged temperature rise of $4.5 \mathrm{~K}$ by increasing the effective vegetation fractional coverage from 0.0 to 1.0. Noteworthy, both $C T R L_{h i s t}$ and $M O D I F_{\text {hist }}$ fail in representing the observed cooling over South-East US (Fig. 7). This is primarily due to the fact that the model is not able to represent correctly the positive decadal anomaly that characterized Pacific North American (PNA) pattern and ENSO during the last decades (Trenberth et al. 2007) and so the related teleconnections over Eastern US. The erroneous warming simulated over Eastern US appears to be reinforced by increasing the high vegetation cover (Fig. 8c) and reducing albedo (Fig. 8b) in MODIF hist and therefore leading to further warming over Eastern US.

The effect of the representation of vegetation cover variability is smaller during boreal summer, but still warming effects persists over high latitude Siberia and North America, due to the albedo decrease that is related also to the smaller accumulation of snow compared to CTRL (not shown).

\section{Effect on potential predictability at decadal time scales}

Figure 9 compares the $M O D I F_{d e c}$ and $C T R L_{d e c}$ predictions of $2 \mathrm{~m}$ temperature at 3-year lead time, valid for the 4-5 year forecast period, by computing the correlations of the respective ensemble-mean forecasts with the reference 
SENSITIVITY (MODIF minus CTRL)
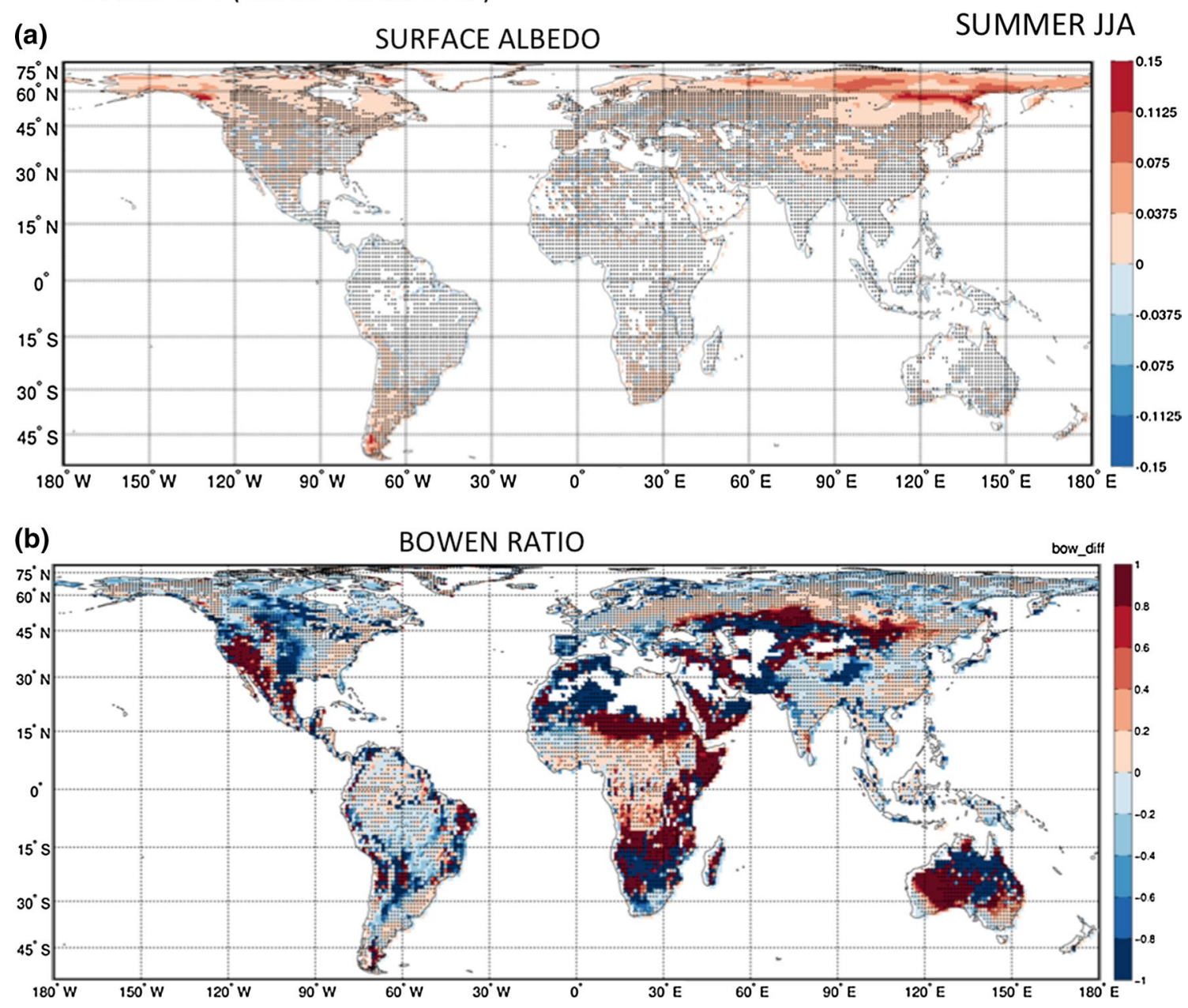

Fig. 6 Same as Fig. 5 but for boreal summer (June-July-August; JJA)

historical simulation $\left(M O D I F_{\text {hist }}\right)$. Figure 9a reports the correlations for the $C T R L_{d e c}$ experiment, while Fig. 9b shows the MODIF-minus-CTRL correlation differences over land. The correlations for the control experiment, in Fig. 9a, are tested for significance by applying a parametric test that uses the Fisher transform. For the correlation differences in Fig. 9b, we tested for each grid point the null hypothesis of getting as high or higher correlation differences simply by chance through a Monte Carlo bootstrap method (1000 repetitions). The results in Fig. 9a show that the potential predictability in $C T R L_{d e c}$ tends to be concentrated over tropical Pacific and Indian Ocean, confirming that much of the potential skill of present dynamical climate forecasts comes from their ability in predicting tropical Sea Surface Temperature (SST) and the connection between Tropical Pacific and Indian Ocean (e.g. Alessandri et al. 2010; Seager et al. 2004). Outside the Pacific and
Indian Oceans, good potential predictability is also found over the tropical and northern Atlantic and Euro-Mediterranean basin. The largest performance tends, however, to be confined over the ocean. Over land, the potential predictability is fair over most of South America and Africa, South-East Asia, Northern China and Mongolia, west of North America, East Canada, Europe and West Russia (Fig. 9a).

The $M O D I F_{d e c}$ experiment displays a significant improvement over Central US Great Plains, Nordeste Brazil, Sahel, South-East Asia including Indian region, subtropical southern Africa and Australia, and boreal forests over East Asia, North America and North-East Europe (Fig. 9b). Overall, the inclusion of the new parameterization leads to enhancements of land-averaged potential skill (Fig. 9c), with a significant correlation improvement for $M O D I F_{d e c}$ at all lead times (5\% significance level). 

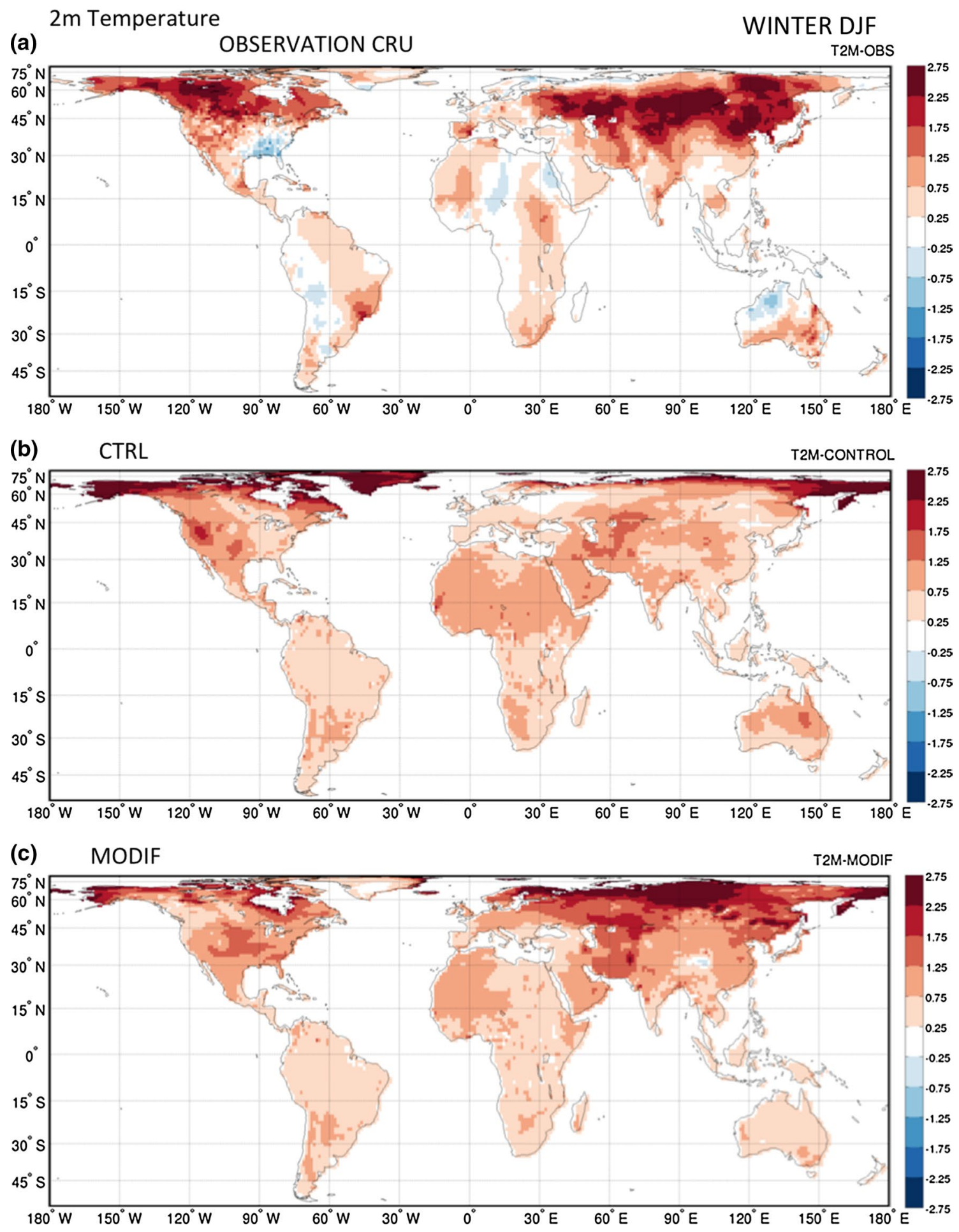

Fig. 7 (2010-1980) minus (1940-1910) boreal winter (DJF) 2 m-temperature change for a observations, and for historical simulations using b $C T R L_{\text {hist }}$ and $\mathbf{c} M O D I F_{\text {hist }}$ versions of EC-Earth 

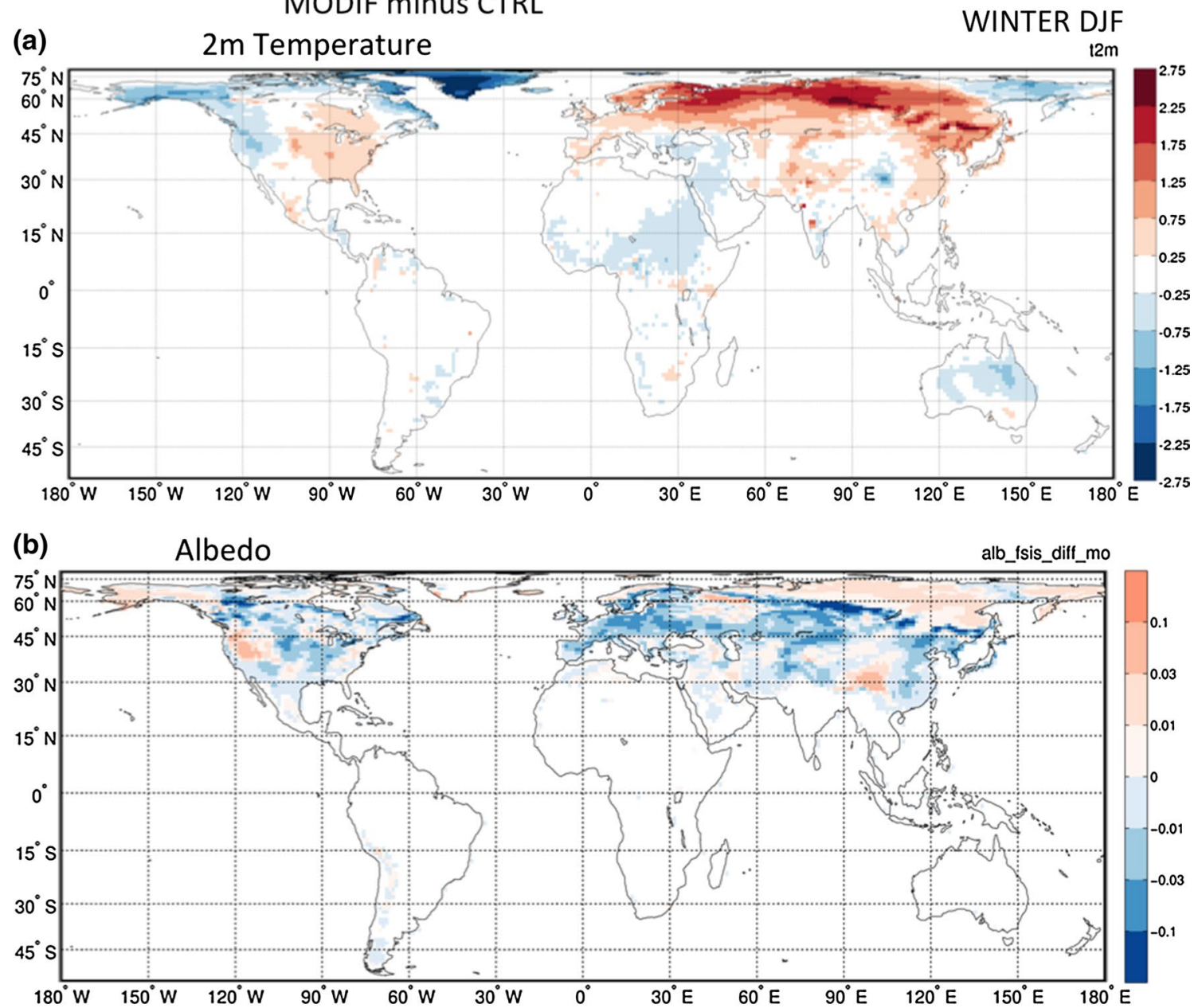

(c) High vegetation cover change

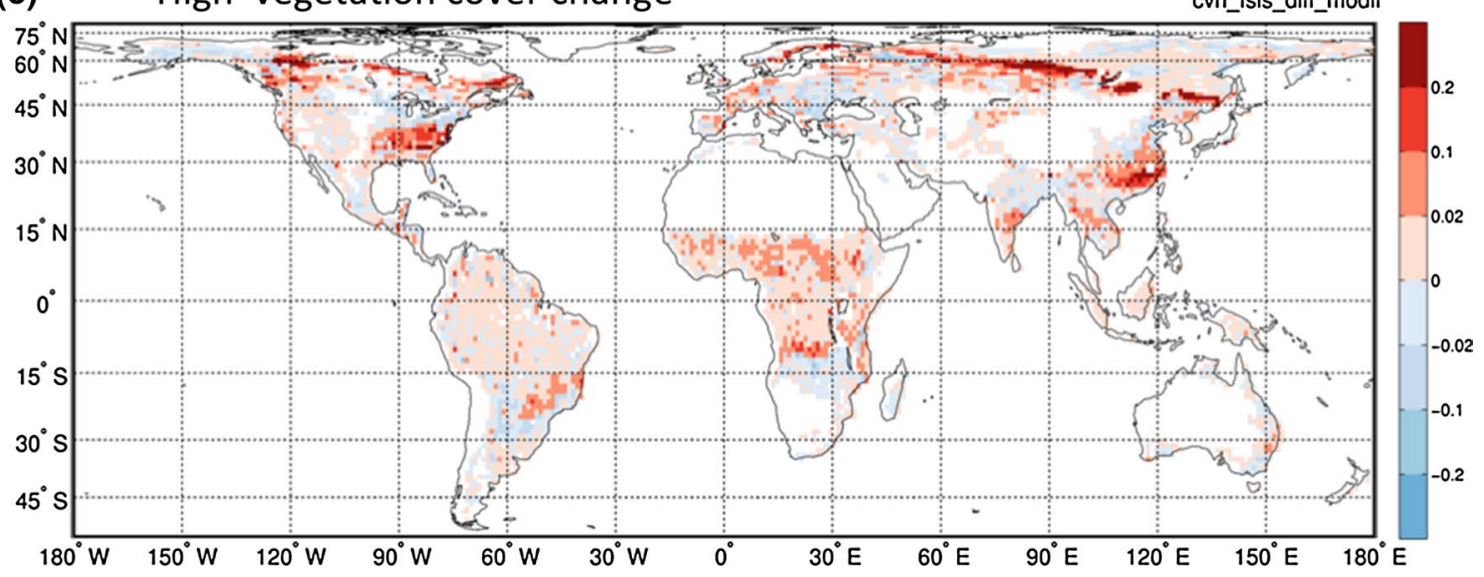

Fig. 8 Sensitivity $\left(M O D I F_{\text {hist }}\right.$ minus $\left.C T R L_{\text {hist }}\right)$ of the (2010-1980) minus (1940-1910) change in boreal winter (DJF) a $2 \mathrm{~m}$ temperature, b albedo and $\mathbf{c}$ high effective vegetation cover 
Fig. 9 Correlations of 2-years mean $\mathrm{T} 2 \mathrm{M}$ predictions at 36-months lead time with the reference historical simulation for a control experiment $\left(C T R L_{d e c}\right)$; b $M O D I F_{d e c}$ versus $C T R L_{d e c}$ differences over land. Areas that did not pass a significance test at $10 \%$ level are dotted. c Global land mean correlations of 1-year mean $\mathrm{T} 2 \mathrm{M}$ as a function of lead time for modified and control experiments. Marks indicate significant difference of the correlations between the two experiments that passed a significance test at $5 \%$ level
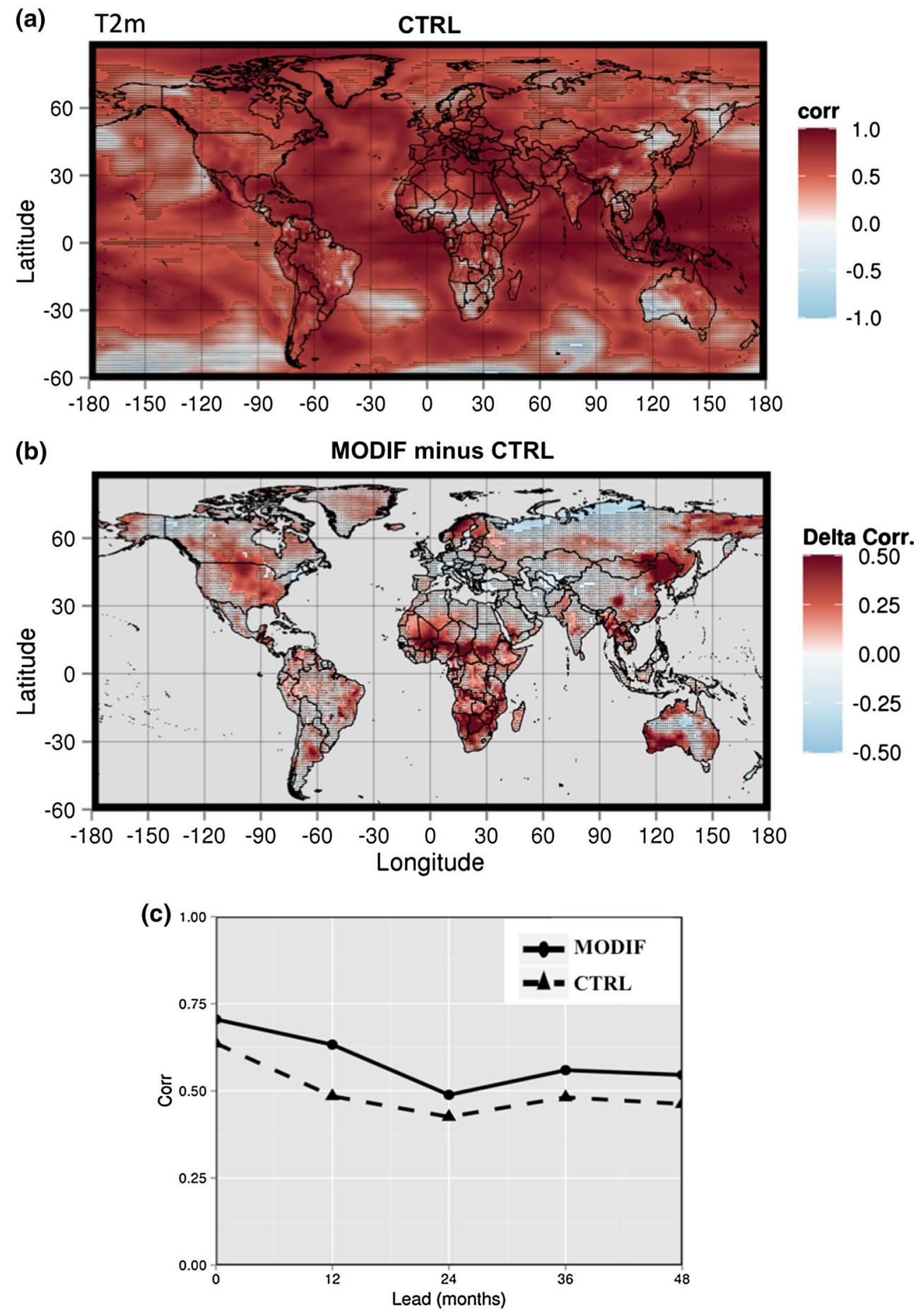

Figure 10 compares $M O D I F_{d e c}$ and $C T R L_{d e c}$ predictions for precipitation. Even if the performance is quite limited for the prediction of the precipitation at 3-years lead (Fig. 10a), a significant improvement with respect to $C T R L_{d e c}$ is found for the $M O D I F_{d e c}$ correlation over North American Great Plains, Nordeste Brazil and Amazon basin, Sahel and most of equatorial Africa, Mediterranean central and eastern Europe, and South-East Asia (Fig. 10b).
Figure 10c compares the globally averaged correlations over land of the precipitation forecasts for the $M O D I F_{d e c}$ and $C T R L_{d e c}$ experiments. The inclusion of the effective vegetation cover variability is found to significantly improve the potential skill in the $M O D I F_{d e c}$ predictions of precipitation at all lead times.

To investigate the predictability enhancement discussed above (see Table 2 for a summary over most 
Fig. 10 Same as Fig. 9 but for precipitation

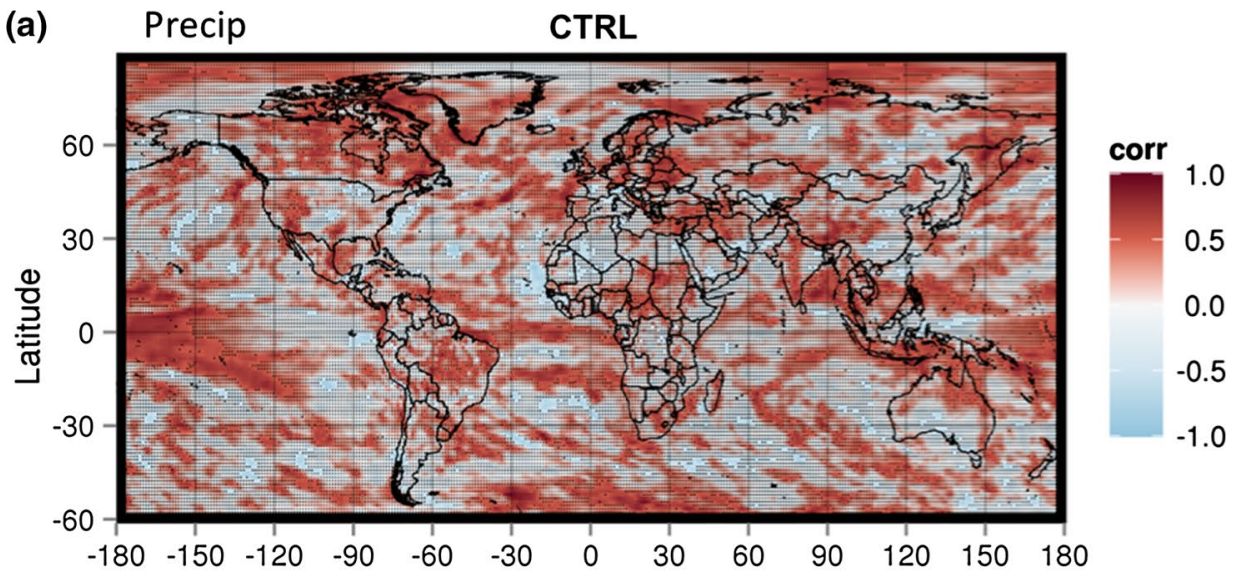

(b) MODIF minus CTRL

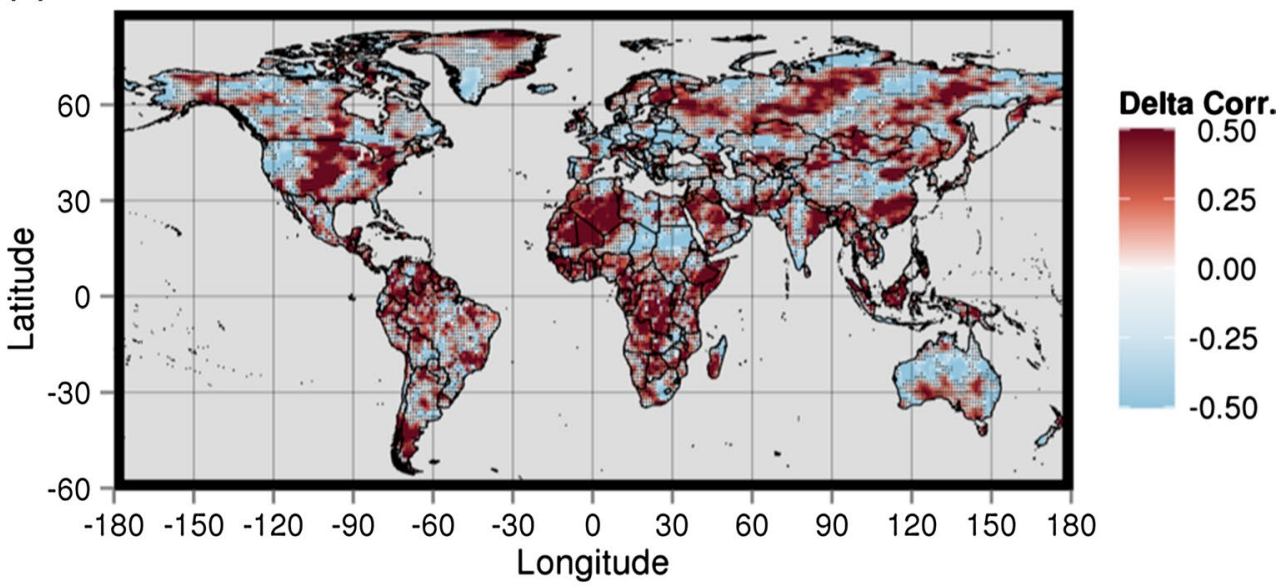

(c)

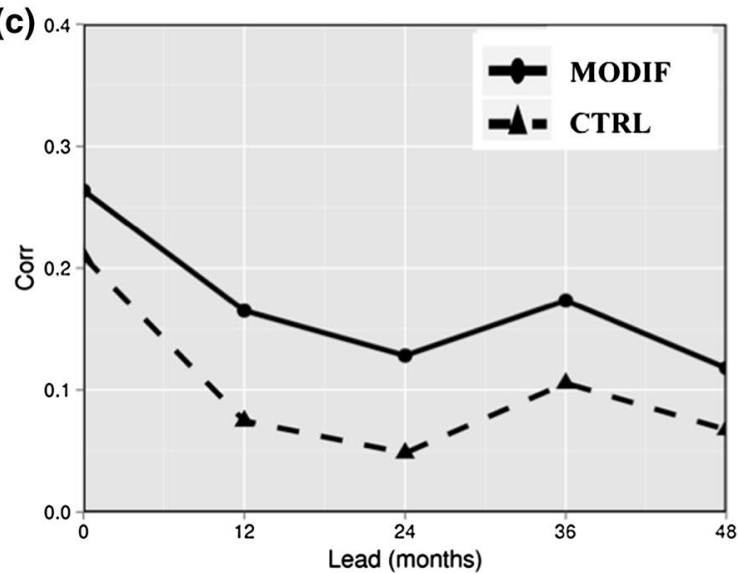

affected regions), the relationships between the improvement of the correlation for the target variables $(2 \mathrm{~m}$-temperature and precipitation) is analyzed with respect to the improvements in the possible surface drivers for the areas of interest in Figs. 9 and 10. For this the correlation coefficient (Eq. 4) is decomposed in its components measuring the covariance between each predicted $\left(x_{i}^{k}\right)$ and reference $\left(y_{i}^{k}\right)$ yearly anomalies [Eq. 5; hereinafter normalized yearly covariance, $\left.r(x, y)_{i}^{k}\right]$. In Eqs. 4-5, superscript $k$ stands for the forecasts lead time, subscript $i$ identifies each forecast start date and $n$ is the total number of forecast start dates; overbars indicate 
(a) T2m vs. albedo

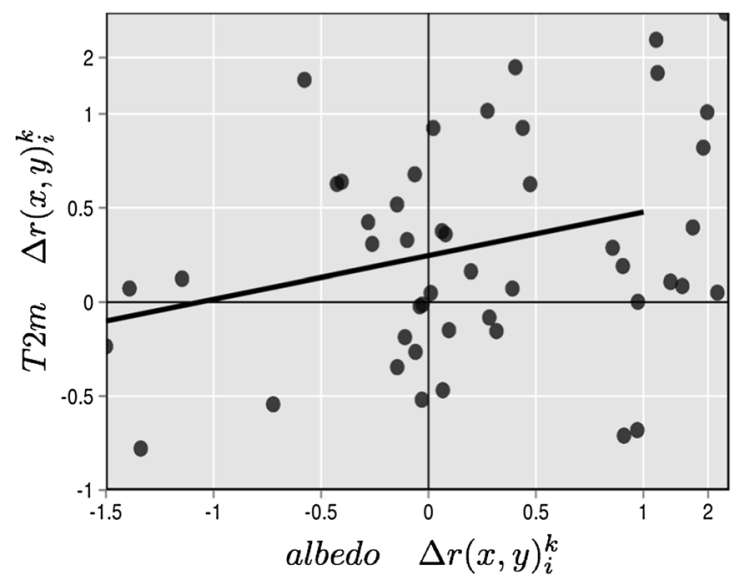

Fig. 11 Scatterplot of the normalized yearly covariance differences between $M O D I F_{d e c}$ and $C T R L_{d e c}\left[\Delta r(x, y)_{i}^{k}\right]$ for the predictions averaged over the East-Asian boreal forest domain $(115 \mathrm{E}-135 \mathrm{E} ; 45 \mathrm{~N}-$ $60 \mathrm{~N}$ ) of a T2m versus albedo and b T2m versus snow-depth. Black filled circles are the normalized yearly covariance differences com- (b)

T2m vs. snow depth

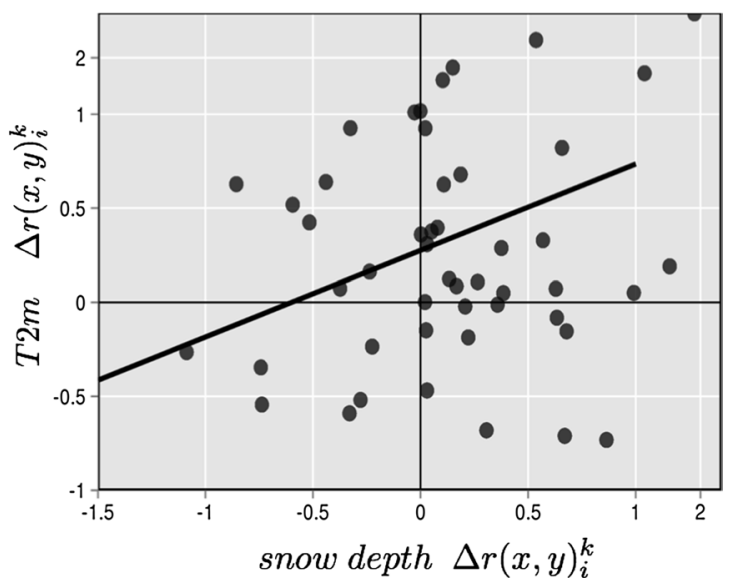

puted for each lead-time $(\mathrm{k}=0,1,2,3,4$ years) and for each start date $(\mathrm{i}=1,2, \ldots, 10)$. Regression line indicate significant $(10 \%$ level $)$ relationship between improved prediction of $\mathrm{T} 2 \mathrm{~m}$ and enhanced a albedo and $\mathbf{b}$ snow depth (a)

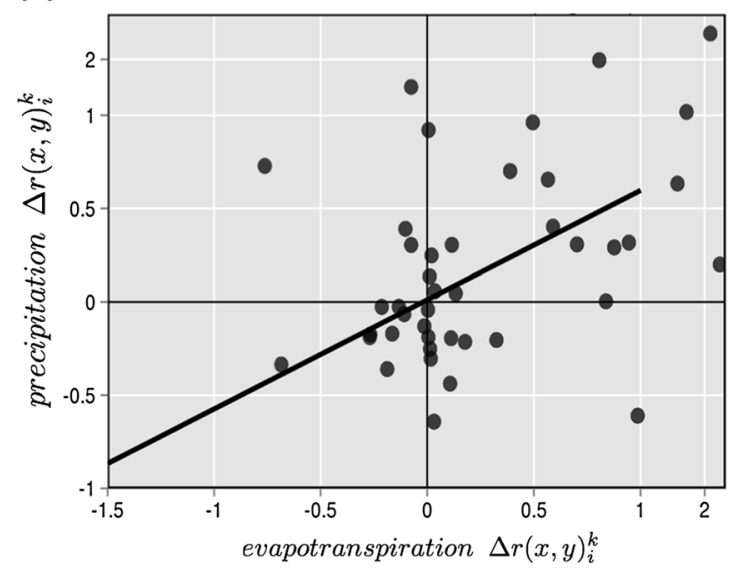

(b) Prec vs. moisture convergence

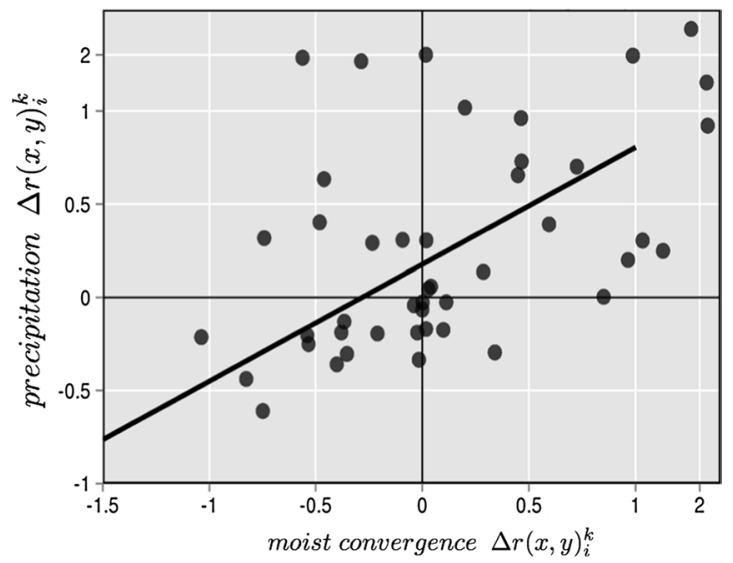

Fig. 12 Same as Fig. 11 but for the predictions averaged over the Sahel domain (15W-30E; 5N-20N) of a precipitation versus evapotranspiration and $\mathbf{b}$ precipitation versus moisture convergence

climatological averages and the primes denote anomalies (subtraction of climatological yearly values).

$$
\begin{aligned}
r(x, y)^{k} & =\frac{\operatorname{Cov}\left(x^{k}, y^{k}\right)}{s_{x}^{k} s_{y}^{k}} \\
& =\frac{\frac{1}{n-1} \sum_{i=1}^{n}\left[\left(x_{i}^{k}-\overline{x^{k}}\right)\left(y_{i}^{k}-\overline{y^{k}}\right)\right]}{\left[\frac{1}{n-1} \sum_{i=1}^{n}\left(x_{i}^{k}-\overline{x^{k}}\right)^{2}\right]^{1 / 2}\left[\frac{1}{n-1} \sum_{i=1}^{n}\left(y_{i}^{k}-\overline{y^{k}}\right)^{2}\right]^{1 / 2}} \\
& =\frac{\sum_{i=1}^{n}\left(x_{i}^{\prime k} y_{i}^{\prime k}\right)}{\left[\sum_{i=1}^{n}\left(x_{i}^{\prime k}\right)^{2}\right]^{1 / 2}\left[\sum_{i=1}^{n}\left(y_{i}^{\prime k}\right)^{2}\right]^{1 / 2}}
\end{aligned}
$$

$r(x, y)_{i}^{k}=\frac{\left(x_{i}^{\prime k} y_{i}^{\prime k}\right)}{\left[\sum_{j=1}^{n}\left(x_{j}^{\prime k}\right)^{2}\right]^{1 / 2}\left[\sum_{j=1}^{n}\left(y_{j}^{\prime k}\right)^{2}\right]^{1 / 2}}$

The $M O D I F_{d e c}$ minus $C T R L_{d e c}$ difference in the normalized yearly covariance $\left[\Delta r(x, y)_{i}^{k}\right]$ considered at all lead times ( $k$ from 0 to 4 years) is analyzed to identify the possible surface drivers for the enhanced predictability of the target variables due to the improved land scheme. To this aim, the linear relation between $\Delta r(x, y)_{i}^{k}$ of the target and driver fields is assessed using 
Table 1 Summary of the experiments

\begin{tabular}{|c|c|c|c|c|c|}
\hline Experiment name & Description & Start dates & Length & Members & Period \\
\hline$M_{O D I F}{ }_{H I S T}$ & $\begin{array}{l}\text { EC-Earth v2.4, coupled with LPJ-Guess; improved historical } \\
\text { simulation }\end{array}$ & - & - & 2 & $1850-2010$ \\
\hline$C T R L_{H I S T}$ & $\begin{array}{l}\text { EC-Earth v2.4, coupled with LPJ-Guess; control historical } \\
\text { simulation }\end{array}$ & - & - & 2 & $1850-2010$ \\
\hline$M O D I F_{D E C}$ & $\begin{array}{l}\text { EC-Earth v2.4, improved decadal predictions in the perfect model } \\
\text { world; LAI prescribed from MODIF } F_{H I S T}\end{array}$ & 1st Jan & 5 years & 7 & 1960-2010 \\
\hline$C T R L_{D E C}$ & $\begin{array}{l}\text { EC-Earth v2.4, control decadal predictions in the perfect model } \\
\text { world; LAI prescribed from MODIF } \\
\text { HIST }\end{array}$ & 1st Jan & 5 years & 7 & 1960-2010 \\
\hline$M_{O D I F_{S E A S}}$ & $\begin{array}{l}\text { EC-Earth v2.4, improved seasonal hindcasts; LAI prescribed from } \\
\text { observations }\end{array}$ & 1st May/1st Nov & 7 months & 10 & 1982-2009 \\
\hline$C T R L_{S E A S}$ & $\begin{array}{l}\text { EC-Earth v2.4, control seasonal hindcasts; LAI prescribed from } \\
\text { observations }\end{array}$ & 1st May/1st Nov & 7 months & 10 & 1982-2009 \\
\hline$M O D I F_{N W P}$ & $\begin{array}{l}\text { Atmosphere-only IFS, improved weather forecasts; climatological } \\
\text { LAI from observations }\end{array}$ & Daily & 4 days & 1 & March 2015 \\
\hline$C T R L_{N W P}$ & $\begin{array}{l}\text { Atmosphere-only IFS, control weather forecasts; climatological } \\
\text { LAI from observations }\end{array}$ & Daily & 4 days & 1 & March 2015 \\
\hline
\end{tabular}
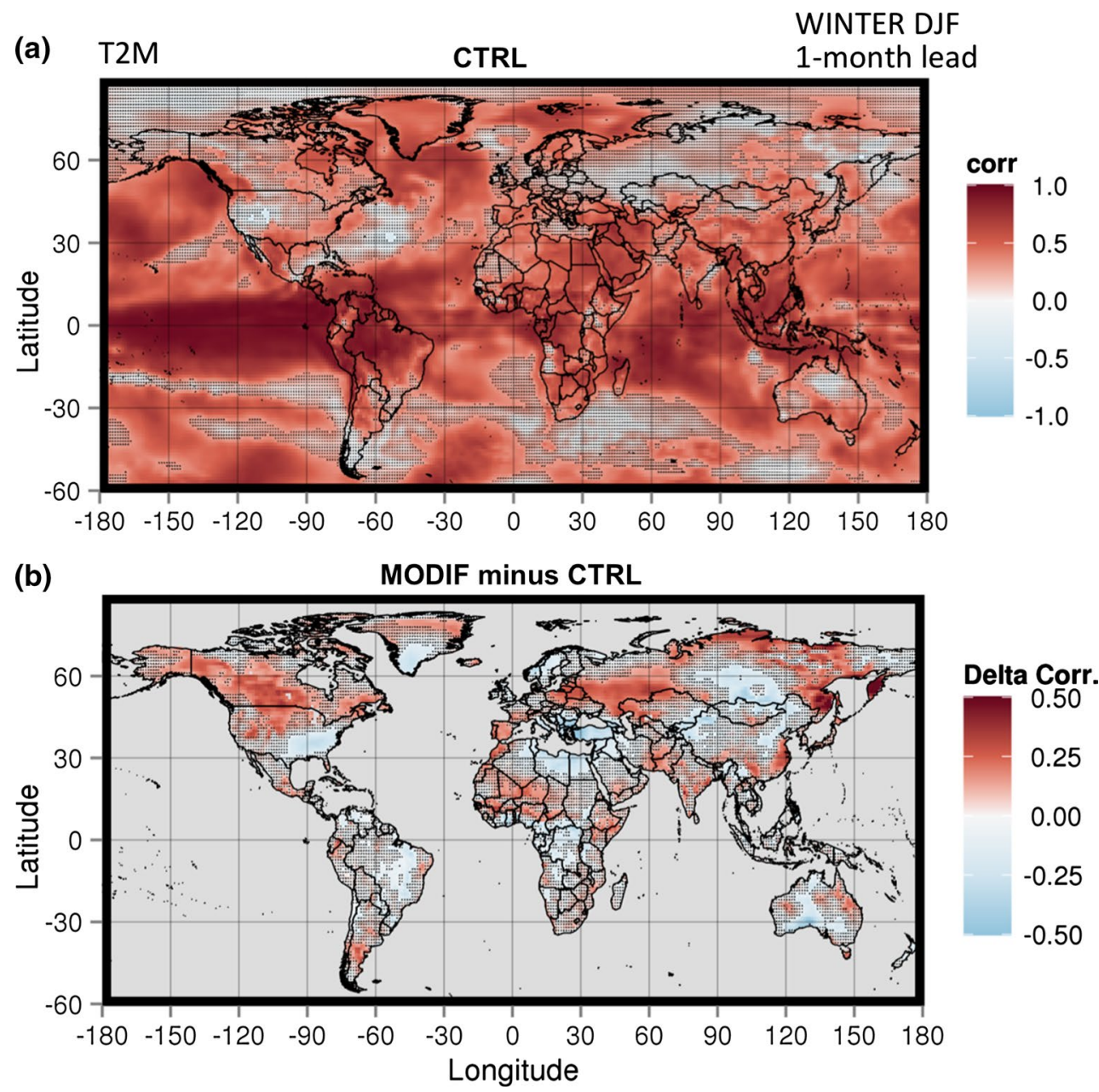

Fig. 13 a $C T R L_{\text {seas }} 1$-month-lead boreal winter (DJF) $2 \mathrm{~m}$ temperature correlation with ERA-INTERIM and b $M O D I F_{\text {seas }}$ minus $C T R L_{\text {seas }}$ correlation difference. Dotted grid points did not pass a significance test at $10 \%$ level 
a least square method and significance of the slope of linear relationship is evaluated using a Fisher parametric test. The positive linear relationship between target and driver in terms of the $M O D I F_{d e c}$ minus $C T R L_{d e c}$ yearly covariance differences $\left[\Delta r(x, y)_{i}^{k}\right]$ indicates the enhanced predictability of the target as mediated by the driver, which is directly affected by the improved land surface scheme. The slope of the relationship between surface driver and target variables is reported in Table 3 for the most affected regions. Only the linear coefficients of the regression that passed significance test at $5 \%$ (marked with two asterisks) and $10 \%$ (one asterisk) are reported in the table. It is important to note that the predictive skill generally depends on the lead time. However, since the main focus here is not in the prediction skill itself but rather in the effect of replacing $C T R L_{d e c}$ by $M O D I F_{d e c}$ to the enhanced predictability of the target as mediated by the driver, we decided to retain all lead times to increase the robustness of the linear fit estimation. Our analysis indicates that the better performance over mid-latitude boreal forests can be attributed to an improvement of the sensitivity of modeled albedo over snow covered areas as coming from the representation of vegetation cover variability. This is shown in Fig. 11 for East-Asian boreal forests $(115 \mathrm{E}-135 \mathrm{E} ; 45 \mathrm{~N}-60 \mathrm{~N})$ showing the scatterplot of the $\Delta r(x, y)_{i}^{k}$ for each forecast start date $(i=1,2, \ldots, 10)$ and for each lead time $(k=0,1, \ldots, 4)$ of $\mathrm{T} 2 \mathrm{~m}$ versus albedo (Fig. 11a) and of T2m versus snow depth (Fig. 11b). The slope of the regression line in Figure $11 \mathrm{a}$ indicates a modest relationship between the enhanced predictability of $\mathrm{T} 2 \mathrm{~m}$ and albedo. Indeed, the fact that most of the years occur in the upper right quadrant indicates that improvements in the prediction of surface albedo also drives enhanced $\mathrm{T} 2 \mathrm{~m}$ forecasts.

Table 2 Summary of potential skill enhancements between MODIF and CTRL decadal predictions

\begin{tabular}{|c|c|c|c|c|}
\hline \multirow[t]{2}{*}{ Domain } & \multicolumn{2}{|c|}{ Temperature skill } & \multicolumn{2}{|c|}{ Precipitation skill } \\
\hline & MODIF & CTRL & MODIF & CTRL \\
\hline $\begin{array}{l}\text { East-Boreal Asia 115E-135E; } \\
45 \mathrm{~N}-60 \mathrm{~N}\end{array}$ & $0.57(* *)$ & 0.24 & 0.01 & -0.07 \\
\hline $\begin{array}{l}\text { South-East Asia 60E-140E; } \\
7 \mathrm{~N}-40 \mathrm{~N}\end{array}$ & 0.80 & 0.82 & $0.57(* *)$ & 0.30 \\
\hline Sahel 15W-30E; 5N-20N & $0.79(* *)$ & 0.70 & $0.55(* *)$ & 0.35 \\
\hline $\begin{array}{l}\text { Central USA } 115 \mathrm{~W}-93 \mathrm{~W} ; \\
25 \mathrm{~N}-50 \mathrm{~N}\end{array}$ & $0.72(* *)$ & 0.52 & $0.31(*)$ & -0.05 \\
\hline $\begin{array}{l}\text { Nordeste Brazil 50W-30W; } \\
\text { 20S-0S }\end{array}$ & $0.69(*)$ & 0.61 & $0.37(*)$ & 0.11 \\
\hline
\end{tabular}

Two (one) asterisks indicate that correlation improvement compared to other experiment passed significance test at $5 \%(10 \%)$ level

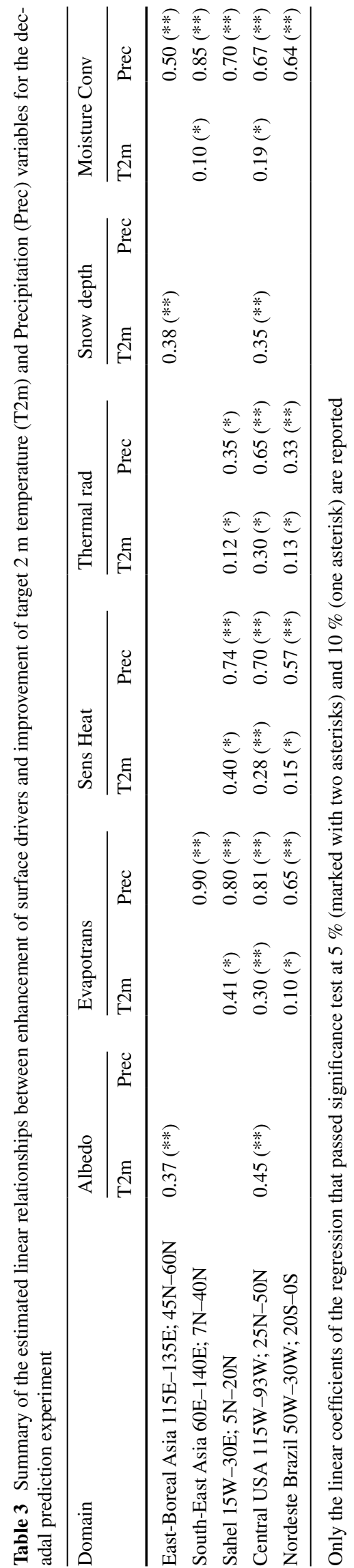




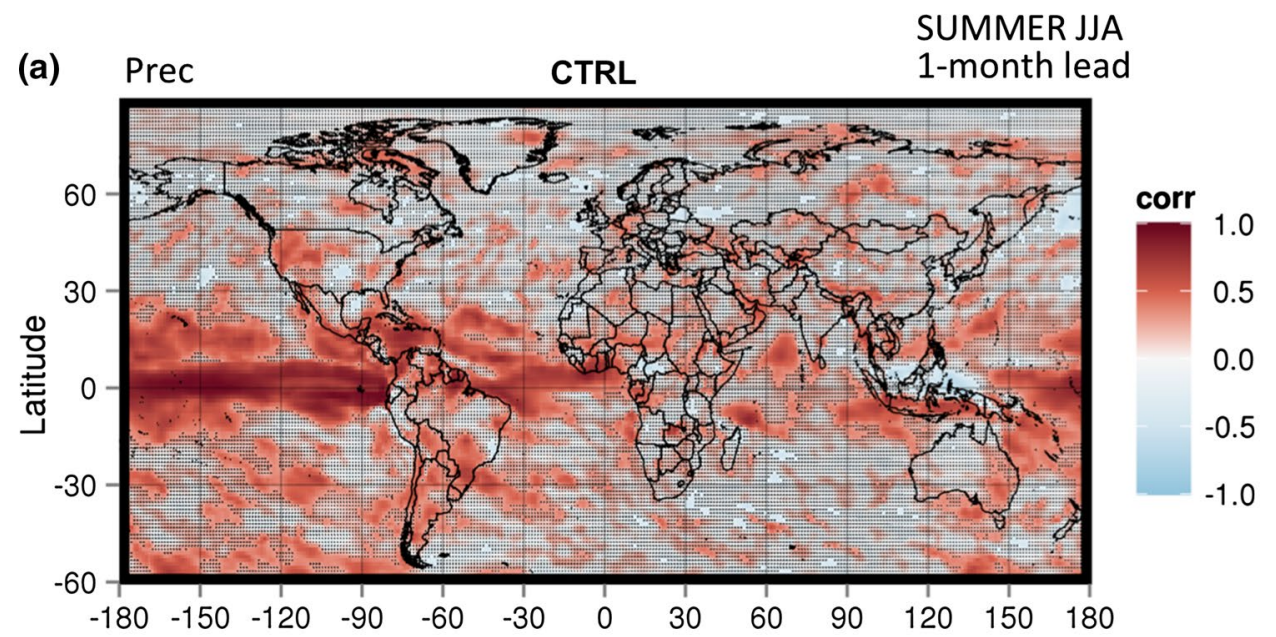

(b) MODIF minus CTRL

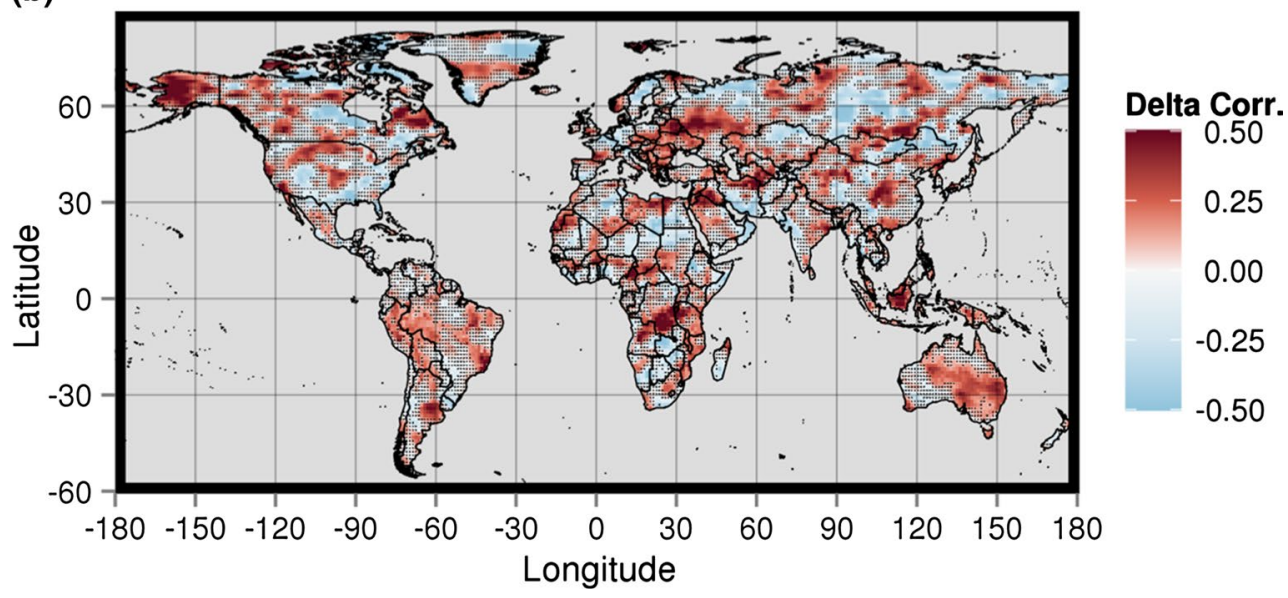

Fig. 14 Same as Fig. 13 but for boreal summer (JJA) precipitation

A quite similar relationship is found between $\mathrm{T} 2 \mathrm{~m}$ and snow depth in Fig. 11b, confirming a positive feedback between snow and albedo over this region (Fernandes et al. 2009).

The precipitation improvements over South East Asia (60E-140E; 7N-40N), Sahel (60E-140E; 7N-40N), US Great Plains (115W-93W; 25N-50N), and Nordeste Brazil $(50 \mathrm{~W}-30 \mathrm{~W} ; 20 \mathrm{~S}-0 \mathrm{~S})$ are significantly related to the effects of the representation of vegetation cover variability on evapotranspiration and related surface partitioning between sensible and latent heat fluxes (Table 3). As shown for the Sahel domain in Fig. 12 the improved prediction of evapotranspiration in $M O D I F_{d e c}$ compared to $C T R L_{d e c}$ also leads to enhanced precipitation forecasts in most of the years (Fig. 12a). The strong relation between precipitation and evapotranspiration appears also coupled with the atmospheric dynamics via a significant enhancement of precipitation normalized yearly covariances due to improved prediction of moisture convergence (Fig. 12b).

\section{Effect on short-term forecasts}

The results for boreal winter (December-January-February; DJF) forecasts started 1st November show that the skill tends to be concentrated over tropical Pacific and, from there, irradiates toward the whole tropical belt and extratropics (Fig. 13a), with the largest skill confined over the ocean. Over land, there is a good skill in South America, Africa, Euro-Mediterranean region, SouthEast Asia and over the southern and eastern part of North America. Figure 13b shows the difference of the correlations with observed $2 \mathrm{~m}$-temperature between $M O D I F_{\text {seas }}$ and $C T R L_{\text {seas }}$ in the ensemble-mean seasonal forecasts at 1-month lead time for the 2-4 month forecast period valid in DJF. For each grid point, we tested the null hypothesis of getting as high or higher correlation differences simply by chance through a Monte Carlo bootstrap method (1000 repetitions). Overall, the performance of $M O D I F_{\text {seas }}$ is better than $C T R L_{\text {seas }}$, especially in the Northern Hemisphere. The 

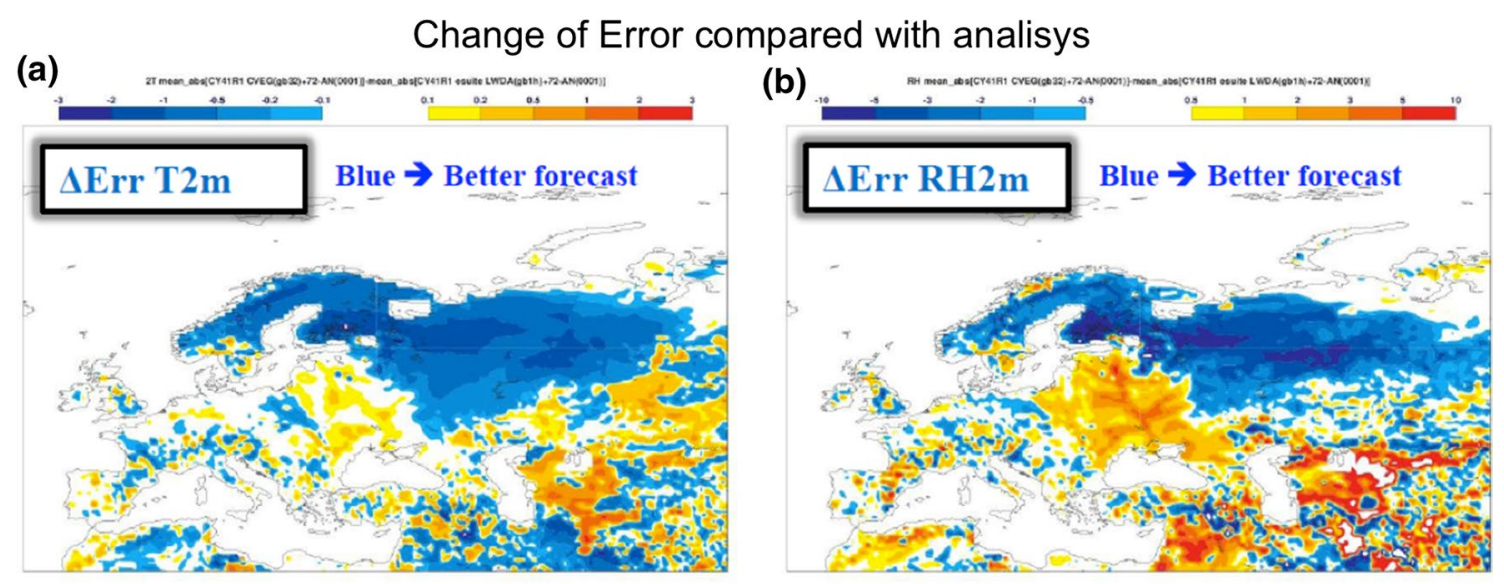

(c)

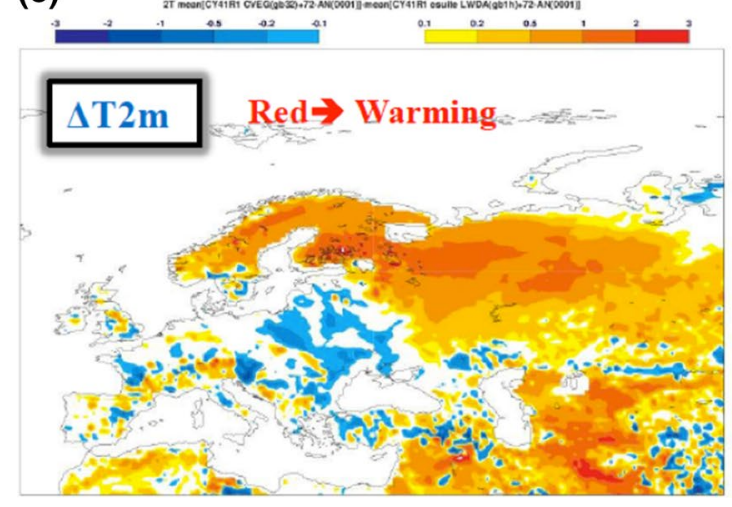

Fig. 15 Weather forecast case study for March 2015 using ECMWF operational 72-h deterministic forecasts. $M O D I F_{N W P}$ minus $C T R L_{N W P}$ a forecast $\mathrm{T} 2 \mathrm{~m}$ error, $\mathbf{b}$ forecast $2 \mathrm{~m}$ relative humidity (RH)

$M O D I F_{\text {seas }}$ experiment displays increased correlations over all the boreal forests, in particular Canada, West US, Eastern Europe, Russia and eastern Siberia. As summarized in Table 4 (rows 1-2), consistent with the climate change and decadal improvements discussed above (see Sects. 3, 4), this can be primarily attributed to the better representation of the albedo variability resulting from the introduced variability of the effective vegetation cover and of the related shadowing effect on snow cover in those regions.

Significant improvements are also evident over transitional land-surface hot spots such as the Sahel, South East Asia including the Indian Subcontinent, continental North American Great Plains and Eastern Europe. In the southern hemisphere the difference is smaller, with significant differences limited to some parts of Argentina, Africa and north-eastern Australia.

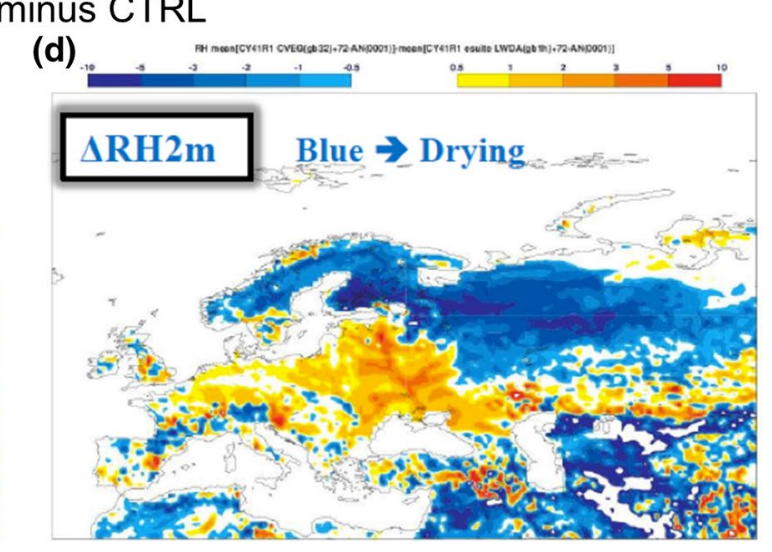

error, $\mathbf{c}$ forecast $\mathrm{T} 2 \mathrm{~m}$ anomaly and $\mathbf{d}$ forecast $\mathrm{RH}$ anomaly. Errors are computed with respect to ECMWF operational analysis

The differences of correlation for $2 \mathrm{~m}$-temperature in boreal summer (June-July-August, JJA; not shown) are smaller than for DJF. Nevertheless, significant improvements are still observed over Europe, central Asia, the Great Plains of North America, Argentina, Nordeste and high-latitude forests (Alaska and Siberia). Figure 14 compares $M O D I F_{\text {seas }}$ and $C T R L_{\text {seas }}$ 1-month-lead ensemblemean JJA forecasts for precipitation. The correlation improvement of the $M O D I F_{\text {seas }}$ hindcasts for precipitation is noticed over several transitional land regions also showing enhancements for $2 \mathrm{~m}$-temperature (not shown), and are concentrated over south-eastern Europe/western Russia, Sahel, the Great Plains of North America, Alaska, Nordeste, Peru and La Plata basin. It is noted however that the pattern of improvement for precipitation tends to be more patchy compared to results for temperature. As reported in 
Table 4 (rows 3-6), the JJA improvement over transitional hot spot regions, such as South-East Asia, Sahel, US Great Plains and Nordeste Brazil, in $M O D I F_{\text {seas }}$ is at least in part attributed to improved representation of evapotranspiration. For Sahel, US Great Plains and Nordeste Brazil, the improvement for precipitation is also related to the better partitioning at the surface between sensible and latent heating. A significant coupling with atmospheric dynamics and moisture convergence is also reported in South East Asia, Sahel, and US Great Plains (Table 4, rows 3-6).

\subsection{Case study on march 2015 weather forecasts over Europe}

In March 2015 the ECMWF weather forecasts over the northeastern Europe boreal forests, using the original version of the HTESSEL model $\left(C T R L_{N W P}\right)$, were affected by cold errors on $2 \mathrm{~m}$ temperature up to $4 \mathrm{~K}$ over Scandinavia region and with moist bias on $2 \mathrm{~m}$ specific humidity of around $1 \mathrm{~g} / \mathrm{kg}$ compared to the ECMWF operational analysis (http://www.ecmwf.int/). These biases were substantially reduced (Fig. 15a, b) when using the new $M O D I F_{N W P}$ version of the model leading to a warming and drying over Scandinavia and northeastern Europe (Fig. 15c, d). Consistent with the effects on winter biases (Sect. 3.1), climate change sensitivity (Sect. 3.2) and seasonal-to-decadal predictability improvements discussed above (see Sects. 4, 5), the error reductions over mid-latitude northeastern Europe boreal forests in $M O D I F_{N W P}$ are mainly attributed to the adjustment of the surface albedo. In fact, the increased shadowing of the snow beneath the high vegetation, in $M O D I F_{N W P}$, leads to corresponding albedo decreases over Scandinavian, East European and West Russian boreal forests (Fig. 16) that reduce the cold biases over these regions.

\section{Conclusions}

The newly introduced representation of the effective vegetation cover variability (MODIF experiments), by including an exponential dependence of the vegetation density to LAI, leads to an unprecedented enhancement of the ECEarth performance across scales over areas where the landatmosphere coupling is strong. Particularly large effects are shown over boreal winter middle-to-high latitudes over Eastern Europe, Russia, eastern Siberia, Canada and West US due to the implemented time-varying shadowing effect by tree-vegetation on snow surfaces. For present-day simulations (1980-2010), the cooling effect of the new parameterization, due to the albedo increase following the reduced shadowing by the tree-vegetation during winter, significantly corrects the warm bias of EC-Earth in those regions. Over the same boreal forest regions, MODIF reproduces 


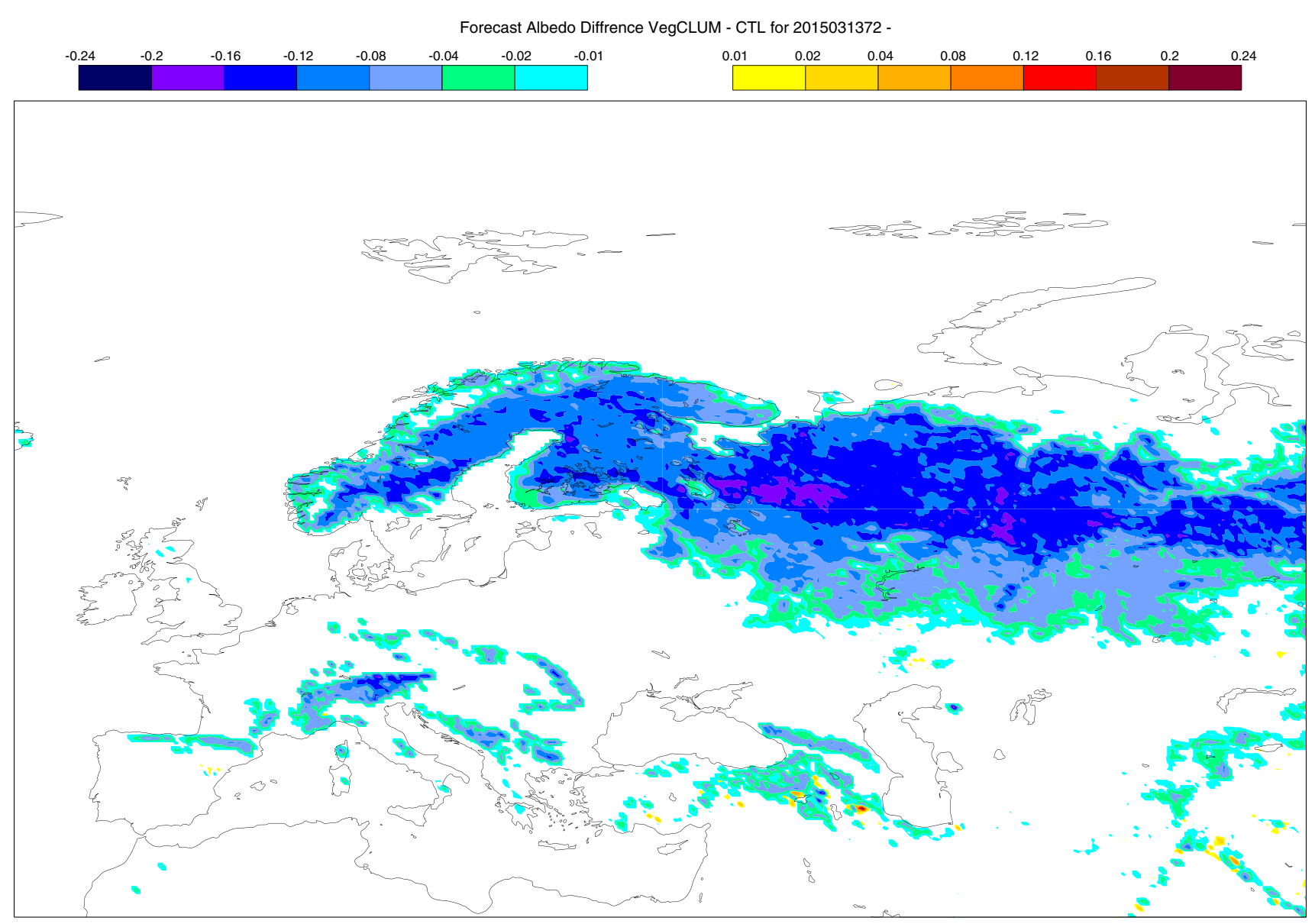

Fig. 16 Weather forecast case study for March 2015 using ECMWF operational 72-h deterministic forecasts. MODIF minus CTRL surface albedo

much better the temperature change signal observed during the last century with respect to control (CTRL). Again, the main mechanism is related to the albedo and due to the increased shadowing of snow by the high-tree vegetation. In fact, the warmer conditions over middle-to-high latitudes driven by the radiative climate-change forcing lead to increased LAI and effective high-vegetation cover for $M O D I F$, therefore inducing a positive feedback on temperature increase during the last century. In this respect, it is estimated that increasing the effective vegetation fractional coverage from zero to one would lead to an averaged temperature rise of $4.5 \mathrm{~K}$ over snow covered boreal forest regions. The representation of the effective vegetation cover variability in MODIF also leads, over mid-latitude boreal forest regions, to enhanced potential predictability at decadal (up to 5 years) scale and to enhanced skill of the winter (DJF) seasonal forecasts. The analysis indicates that the better performance, at both seasonal and decadal timescales, over mid-latitude boreal forests can be attributed to the improvement in forecasting surface albedo over snow covered areas that follows from the realistic representation of vegetation cover variability. This is further verified at the shorter weather forecast time-scale by applying the atmosphere-only ECMWF operational weather forecasting system at 72-h lead time. Focusing on the European domain for the March 2015 case study, the realistic representation of vegetation cover variability substantially corrects the cold prediction errors on $2 \mathrm{~m}$ temperature of up to $4 \mathrm{~K}$ and on $2 \mathrm{~m}$ specific humidity of about $1 \mathrm{~g} / \mathrm{Kg}$ centered over the Scandinavia region.

The representation of the effective vegetation cover variability in MODIF has significant effects on the predictability of $2 \mathrm{~m}$ temperature and rainfall over transitional land-surface hot spots as the Sahel, North American Great Plains, Nordeste Brazil and South East Asia. Even if displaying some mixed results due to the unavoidable internal noise, the MODIF rainfall forecasts are improved in many land areas also showing enhancement for $2 \mathrm{~m}$-temperature. At the decadal time-scale (up to 5 years), the improvements in potential predictability 
over transitional land-surface hot spots are strongly related to the effects of the newly introduced effective vegetation cover variability on evapotranspiration and on the better partitioning of surface fluxes between sensible and latent heating. The potential skill improvements at decadal time-scales for precipitation is mostly driven by enhancements in the predictability of evapotranspiration. The better precipitation predictability appears also coupled with the atmospheric dynamics. In fact, a significant relation between improved potential predictability of precipitation and of atmospheric moisture convergence is also found over these hot spot regions. At the seasonal time-scale, the MODIF retrospective predictions at 1-month lead time also display improvements over transitional land surface hot spots. Noticeable skill enhancement is found for the seasonal forecasts of precipitation in boreal summer over transitional land regions also showing enhancement for $2 \mathrm{~m}$-temperature, particularly over Sahel, continental North America including Great Plains, Nordeste, South-East Asia and south-eastern Europe/western Russia. The improvement is at least in part related to the better prediction of evapotranspiration in MODIF. For Sahel, US Great Plains and South East Asia the skill enhancement for precipitation is also coupled with the improved prediction of atmospheric moisture convergence. A comprehensive assessment of the $M O D I F$ versus $C T R L$ seasonal forecast enhancements, in terms of probabilistic scores, will be discussed in a paper currently under submission by Catalano et al. (2016).

In this paper we show for the first time an encouraging enhancement across scales of climate simulation and prediction due to a more realistic representation of landvegetation processes. This motivates further works to introduce those land vegetation processes that can improve the performance and usefulness of the predictions. As the next step in the development of EC-Earth, we plan to introduce a fully interactive land albedo scheme able to suitably discriminate between vegetation and soil. By replacing the current parameterization that prescribes time-invariant blended albedo for the portions of the grid points that are not covered by snow, this is expected to bring additional beneficial effects on climate simulation and prediction across time-scales.

Acknowledgments This work was supported by the European Union Seventh Framework Programme (FP7/2007-13) under Grant 308378 (SPECS Project; http://specs-fp7.eu/). The ECMWF experiments were supported by the EU-FP7 ImagineS project (http://fp7-imagines. $\mathrm{eu} /$ ) in support to the Copernicus Global land. Further support was provided to this work by the European Union's Horizon 2020 research and innovation programme under grant agreement N. 641816 (CRESCENDO project; http://crescendoproject.eu/) and under grant agreement N. 704585 (PROCEED project). Acknowledgement is made for the use of ECMWF's computing and archive facilities in this research (special project SPITALES).
Open Access This article is distributed under the terms of the Creative Commons Attribution 4.0 International License (http://creativecommons.org/licenses/by/4.0/), which permits unrestricted use, distribution, and reproduction in any medium, provided you give appropriate credit to the original author(s) and the source, provide a link to the Creative Commons license, and indicate if changes were made.

\section{References}

Adler RF et al (2003) The version-2 global precipitation climatology project (GPCP) monthly precipitation analysis (1979-present). J Hydrometeorol 4:1147-1167

Alessandri A, Gualdi S, Polcher J, Navarra A (2007) Effects of land surface-vegetation on the boreal summer surface climate of a GCM. J Clim 20:255-277. doi:10.1175/JCLI3983.1

Alessandri A, Navarra eA (2008) On the coupling between vegetation and rainfall inter-annual anomalies: possible contributions to seasonal rainfall predictability over land areas. Geophys Res Lett 35:L02718. doi:10.1029/2007GL032415

Alessandri A, Borrelli A, Masina S, Pietro PD, Carril AF, Cherchi A, Gualdi S, Navarra A (2010) The CMCC-INGV seasonal prediction system: improved ocean initial conditions. Mon Weather Rev 138:2930-2952. doi:10.1175/2010MWR3178.1

Balsamo G, Beljaars A, Scipal K, Viterbo P, van den Hurk B, Hirschi M, Betts AK (2009) A revised hydrology for the ECMWF model: verification from field site to terrestrial water storage and impact in the integrated forecast system. J Hydrometeorol 10:623-643. doi:10.1175/2008JHM1068.1

Balsamo G, Albergel C, Beljaars A, Boussetta S, Brun E, Cloke H, Dee D, Dutra E, Muoz-Sabater J, Pappenberger F, de Rosnay P, Stockdale T, Vitart F (2015) ERA-Interim/Land: a global land surface reanalysis data set. Hydrol Earth Syst Sci 19:389-407. doi:10.5194/hess-19-389-2015

Berrisford P, Dee D, Fielding K, Fuentes M, Kallberg P, Kobayashi S, Uppala S (2009) The ERA-Interim archive. Technical ERA report series 1, ECMWF, Reading, United Kingdom

Bonan G (2008) Ecological climatology concepts and applications, 2nd edn. Cambridge University Press, Cambridge

Bonavita M, Hólm E, Isaksen L, Fisher M (2016) The evolution of the ECMWF hybrid data assimilation system. Q J R Meteorol Soc 142:287-303. doi:10.1002/qj.2652

Boussetta S, Balsamo G, Beljaars A, Kral T, Jarlan L (2013) Impact of a satellite derived Leaf Area Index monthly climatology in a global Numerical Weather Prediction model. Int J Remote Sens 34(910):3520-3542

Boussetta S, Balsamo G, Dutra E, Beljaars A, Albergel C (2015) Assimilation of surface albedo and vegetation states from satellite observations and their impact on numerical weather prediction. Remote Sens Environ 163:111-126

Catalano F, Alessandri A, De Felice M (2016) Vegetation contribution to seasonal climate prediction (under submission)

Dee D et al (2011) The ERA-Interim reanalysis: configuration and performance of the data assimilation system. Q J R Meteorol Soc 137:553-597. doi:10.1002/qj.828

Du H, Doblas-Reyes FJ, Garcia-Serrano J, Guemas V, Soufflet Y, Wouters B (2012) Sensitivity of decadal predictions to the initial atmospheric and oceanic perturbations. Clim Dyn 39:20132023. doi:10.1007/s00382-011-1285-9

ECMWF (2007) IFS documentation CY31R1-operational implementation 12 September 2006, ECMWF. https://software.ecmwf. int/wiki/display/IFS/CY31R1+Official+IFS+Documentation

ECMWF (2015) IFS documentation CY41R1-operational implementation 12 May 2015, ECMWF. https://software.ecmwf.int/ wiki/display/IFS/CY41R1+Official+IFS+Documentation 
Fernandes R, Zhao H, Wang X, Key J, Qu X, Hall A (2009) Controls on Northern Hemisphere snow albedo feedback quantified using satellite Earth observations. Geophys Res Lett 36:L21702. doi:1 0.1029/2009GL040057

Fichefet T, Morales Maqueda MA (1997) Sensitivity of a global sea ice model to the treatment of ice thermodynamics and dynamics. J Geophys Res 102:12609-12646

Guemas V, Doblas-Reyes FJ, Mogensen K, Keeley S, Tang Y (2014) Ensemble of sea ice initial conditions for interannual climate predictions. Clim Dyn 43:2813-2829. doi:10.1007/ s00382-014-2095-7

Guillevic P, Koster RD, Suarez MJ, Bounoua L, Collatz GJ, Los SO, Mahanama SPP (2002) Influence of the interannual variability of vegetation on the surface energy balance-a global sensitivity study. J Hydrometeorol 3:617-629

Harris I, Jones PD, Osborn TJ, Lister DH (2014) Updated high-resolution grids of monthly climatic observations the CRU TS3.10 Dataset. Int J Climatol 34:623-642. doi:10.1002/joc.3711

Hazeleger W et al (2012) EC-Earth v2.2: Description and validation of a new seamless earth system prediction model. Clim Dyn 39:26112629. doi:10.1007/s00382-011-1228-5

Hartman DL (1994) In: Dmowska R, Holton JR (eds) Global physical climatology. International geophysics series, vol. 56, Academic Press

Hoskins BJ (2013) The potential for skill across the range of the seamless weather-climate prediction problem: a stimulus for our science. Q J R Meteorol Soc 139:573-584. doi:10.1002/qj.1991

Krinner $\mathrm{G}$ et al (2005) A dynamic global vegetation model for studies of the coupled atmosphere-biosphere system. Glob Biogeochem Cycles 19(GB1015):2003G. doi:10.1029/B002199

Lawrence DM, Slingo JM (2004) An annual cycle of vegetation in a GCM. Part I: implementation and impact on evaporation. Clim Dyn 22:87-105. doi:10.1007/s00382-003-0366-9

Madec G (2008) NEMO ocean engine. Note du Pole de modelisation, Institut Pierre-Simon Laplace (IPSL), France, No 27, ISSN No 1288-1619

Magnusson L, Leutbecher M, Kallen E (2008) Comparison between singular vectors and breeding vectors as initial perturbations for the ECMWF ensemble prediction system. Mon Weather Rev 134:4092-4104

Mogensen K, Balmaseda MA, Weaver A (2012) The NEMOVAR ocean data assimilation as implemented in the ECMWF ocean analysis for system 4. ECMWF technical memorandum No. 657

Moss RH et al (2010) The next generation of scenarios for climate change research and assessment. Nature 463:747-756. doi: 10.1038 /nature 08823

Meehl GA et al (2009) Decadal prediction: can it be skillful? Bull Am Meteorol Soc 90:1467-1485. doi:10.1175/2009BAMS2778.1

Myneni RB, Hoffman S, Knyazikhin Y, Privette JL, Glassy J, Tian Y, Wang Y, Song X, Zhang Y, Smith GR, Lotsch A, Friedl M, Morisette JT, Votava P, Nemani RR, Running SW (2002) Global products of vegetation leaf area and fraction absorbed PAR from year one of MODIS data. Remote Sens Environ $83: 214-231$

Orsolini YJ, Senan R, Balsamo G, Doblas-Reyes FJ, Vitart F, Weisheimer A, Carrasco A, Benestad RE (2013) Impact of snow initialization on sub-seasonal forecasts. Clim Dyn 41:1969-1982. doi:10.1007/s00382-013-1782-0
Seager R, Karspeck AR, Cane MA, Kushnir Y, Giannini A, Kaplan A, Kerman B, Velez J (2004) Predicting pacific decadal variability. In: Wang C, Xie SP, Carton JA (eds) Earth's climate. American Geophysical Union, Washington, DC. doi:10.1029/147GM06

Shukla J (2009) Seamless prediction of weather and climate: A new paradigm for modelling and prediction research. US NOAA Climate Test Bed Joint Seminar Series, NCEP

Smith B, Prentice IC, Sykes MT (2001) Representation of vegetation dynamics in the modelling of terrestrial ecosystems: comparing two contrasting approaches within European climate space. Glob Ecol Biogeogr 10:621-637. doi:10.1046/j.1466-822X.2001.00256.x

Sterl A, Bintanja R, Brodeau L, Gleeson E, Koenigk T, Schmith T, Semmler T, Severijns C, Wyser K, Yang S (2012) A look at the ocean in the EC-Earth climate model. Clim Dyn 39:26312657. doi:10.1007/s00382-011-1239-2

Sutton RT, Dong B, Gregory JM (2007) Land/sea warming ratio in response to climate change: IPCC AR4 model results and comparison with observations. Geophys Res Lett 34:L02701. doi:10. 1029/2006GL028164

Taylor KE, Stouffer RJ, Meehl GA (2012) An overview of CMIP5 and the experiment design. Bull Am Meteorol Soc 93:485-498. doi:10.1175/BAMS-D-11-00094.1

Teuling AJ, Seneviratne SI (2008) Contrasting spectral changes limit albedo impact on land-atmosphere coupling during the 2003 European heat wave. Geophys Res Lett 35:L03401. doi:10.102 9/2007GL032778

Trenberth KE, Jones PD, Ambenje P, Bojariu R, Easterling D, Klein Tank A, Parker D, Rahimzadeh F, Renwick JA, Rusticucci M, Soden B, Zhai P (2007) Observations: surface and atmospheric climate change. In: Solomon S, Qin D, Manning M, Chen Z, Marquis M, Averyt KB, Tignor M, Miller HL (eds) Climate change 2007: the physical science basis. Contribution of Working Group I to the Fourth Assessment Report of the Intergovernmental Panel on Climate Change. Cambridge University Press, Cambridge and New York, NY

van den Hurk BJJM, Viterbo P, Los SO (2003) Impact of leaf area index seasonality on the annual land surface evaporation in a global circulation model. J Geophys Res 108(D6):4191. doi:10.1029/2002jd002846

Weiss M, van den Hurk B, Haarsma R, Hazeleger W (2012) Impact of vegetation variability on potential predictability and skill of ECEarth simulations. Clim Dyn 39:2733-2746

Weiss M, Miller P, van den Hurk B, van Noije T, Stefanescu S, Haarsma R, van Ulft LH, Hazeleger W, Le Sager P, Smith B, Schurges G (2014) Contribution of dynamic vegetation phenology to decadal climate predictability. J Clim. doi:10.1175/ JCLI-D-13-00684.1

World Meteorological Organization (2015) In: Brunet G, Jones S, Ruti PM (eds)Seamless prediction of the earth system: from minutes to months. WMO No.1156, ISBN: 978-92-63-11156-2, Geneva

Zhu Z, Bi J, Pan Y, Ganguly S, Anav A, Xu L, Samanta A, Piao S, Nemani RR, Myneni RB (2013) Global data sets of vegetation leaf area index (LAI) $3 \mathrm{~g}$ and fraction of photosynthetically active radiation (FPAR)3g derived from global inventory modeling and mapping studies (GIMMS) normalized difference vegetation index (NDVI3g) for the period 1981 to 2011. Remote Sens 5:927-948 